\title{
Systematic Literature Review and Meta-Analysis of the Relationship Between Polyunsaturated and Trans Fatty Acids During Pregnancy and Offspring Weight Development
}

\section{OPEN ACCESS}

Edited by:

Esther Molina-Montes, University of Granada, Spain

Reviewed by:

Ángela Hernández-Ruiz,

Fundación Iberoamericana de

Nutrición (FINUT), Spain

Carla Ferreri,

National Research Council (CNR), Italy

*Correspondence:

Xuan Ren

xuan.ren@regionh.dk

Specialty section:

This article was submitted to

Nutritional Epidemiology,

a section of the journal

Frontiers in Nutrition

Received: 03 November 2020 Accepted: 17 February 2021 Published: 25 March 2021

Citation:

Ren X, Vilhjálmsdóttir BL, Rohde JF Walker KC, Runstedt SE, Lauritzen L, Heitmann BL and Specht IO (2021) Systematic Literature Review and Meta-Analysis of the Relationship Between Polyunsaturated and Trans

Fatty Acids During Pregnancy and Offspring Weight Development. Front. Nutr. 8:625596. doi: 10.3389/fnut.2021.625596

\begin{abstract}
Xuan Ren ${ }^{1 *}$, Birgitta Lind Vilhjálmsdóttir ${ }^{1}$, Jeanett Friis Rohde ${ }^{1}$, Karen Christina Walker ${ }^{1}$, Suzanne Elizabeth Runstedt ${ }^{1}$, Lotte Lauritzen ${ }^{2}$, Berit Lilienthal Heitmann ${ }^{1,3,4}$ and Ina Olmer Specht ${ }^{1}$

${ }^{1}$ Research Unit for Dietary Studies at the Parker Institute, Bispebjerg and Frederiksberg Hospital, Copenhagen University Hospital, Copenhagen, Denmark, ${ }^{2}$ Department of Nutrition, Exercise and Sports, Paediatric and International Nutrition, University of Copenhagen, Copenhagen, Denmark, ${ }^{3}$ Sydney Medical School, The Boden Institute of Obesity, Nutrition, Exercise, and Eating Disorders, Sydney University, Sydney, NSW, Australia, ${ }^{4}$ Section for General Medicine, Department of Public Health, University of Copenhagen, Copenhagen, Denmark
\end{abstract}

Eicosapentaenoic acid (EPA), docosahexaenoic acid (DHA), and trans fatty acids (TFAs) may have an impact on offspring weight development. We conducted a systematic review and meta-analysis according to PRISMA guidelines to evaluate whether levels of these fatty acids during pregnancy influenced offspring weight development. Randomized controlled trials (RCTs) with DHA and/or EPA supplementation or cohort studies, which examined levels of DHA, EPA, or TFAs in maternal or neonatal blood samples and recorded offspring weight, were included. Overall, 27 RCTs and 14 observational studies were identified. The results showed that DHA and/or EPA supplementation doses $>650 \mathrm{mg} /$ day resulted in slightly higher birth weight (MD $87.5 \mathrm{~g}$, 95\% $\mathrm{Cl} 52.3-122.6, n=3,831)$ and combined BMl and BMl $z$ score at $5-10$ years (SMD 0.11, 95\% Cl 0.04-0.18, $n=3,220$ ). These results were rated as moderate quality. Results from the observational studies were generally inconsistent. High TFA levels during pregnancy seemed to be associated with lower birth weight. Finally, this review and meta-analysis supports a relationship between high maternal or neonatal DHA and/or EPA levels and higher offspring birth weight and weight in childhood. More high-quality long-term studies are still needed.

Keywords: N-3 LCPUFA, TFA, pregnancy, infant, birth weight, weight in childhood, BMI in childhood

\section{INTRODUCTION}

Infant birth weight and the risk of macrosomia (birth weight above 4,000 g) have increased over the last decades in several industrialized countries (1-3). High birth weight is related to a risk of adverse outcomes at delivery, perinatal mortality, and obesity later in life (4). On the other hand, low birth weight also increases the risk of infant mortality and has negative long-term health consequences, including subnormal growth, non-communicable diseases, poor neurodevelopment, and lower academic achievement (5-8). 
Fetal growth and birth weight are determined by several factors (9), of which maternal dietary intake is considered to play a key role (10). Adequate dietary intake, particularly intake of fatty acids, is important during pregnancy. Fatty acids provide most of the energy that is supplied to the fetus via the placenta, which will obviously affect energy metabolism and storage (11). Furthermore, specific fatty acids, like the n-3 longchain polyunsaturated fatty acids (LCPUFA), eicosapentaenoic acid (EPA), and docosahexaenoic acid (DHA), have been shown to have an impact on duration of gestation and birth weight (12). Previous studies from the Faroe Islands suggest that DHA and/or EPA can increase birth weight by prolonging gestation periods and increasing the fetal growth rate $(13,14)$. During pregnancy, the demand for n-3 LCPUFA is higher than during other periods (15), and guidelines specify that pregnant women should consume more than $300 \mathrm{mg}$ of DHA+EPA per day, of which at least $200 \mathrm{mg}$ should be DHA (16-18). However, most pregnant women do not meet the EPA+DHA intake recommendation (19).

Eight previous systematic reviews of randomized clinical trials (RCTs) with n-3 LCPUFA (most included studies investigated the effect of DHA and/or EPA) supplementation during pregnancy and childhood growth have however shown conflicting results $(12,20-26)$. Most of the reviews included RCTs that examined effects of n-3 LCPUFA supplementation already during pregnancy, while two of the reviews included RCTs in which the intervention started during pregnancy and lactation $(21,24)$. Meta-analyses in four of the reviews showed increased birth weight in the DHA- and/or EPA-supplemented groups, and the mean difference between intervention groups and control groups ranges from 42.2 to $122.1 \mathrm{~g}(12,20,21,26)$. One review found that increase in birth weight in DHA and/or EPA in the supplemented group might be caused by an increase in the length of gestation (12). However, other meta-analyses found no association with birth weight $(22,23)$, BMI, or BMI $z$ score measured between 1 and 19 years of age (12, 21, 24, 25). The meta-analyses in the eight systematic reviews were based on different numbers of RCTs-from 6 to 43. Only one of the previous systematic reviews investigated effects among women with healthy pregnancies only (22), whereas six included RCTs with focus on high-risk pregnancies (allergic disease, gestational diabetes, obesity, and preterm birth depressive symptoms) (12, $20,21,23,25,26)$ or RCTs with intervention starting during lactation (24). The DHA and/or EPA dose in the RCTs varied, and it is likely that this would be of importance, but the effect of dose was only investigated in one of the previous reviews (12). This review reported high doses of DHA and/or EPA (more than $500 \mathrm{mg} /$ day) during pregnancy associated with higher birth weight than low doses (12). There are an additional number of observational studies in the field, but to date, no systematic reviews have synthesized the collective evidence for an association between maternal n-3 LCPUFA status during pregnancy and birth outcomes and child growth. Because of the mixed results shown in the meta-analysis and the unknown effect of various doses, it is necessary to continue to perform further studies as well as systematic reviews and meta-analysis of results from both RCTs and observational studies.
There are two major sources of trans fatty acids (TFAs), industrial TFA (iTFA), and ruminant TFA (rTFA). iTFAs are formed by hydrogenation of vegetable oils, and rTFAs are produced by bio-hydrogenation in the rumen of animals (27). TFAs have been shown to be inversely associated with n-3 LCPUFA in maternal serum during pregnancy (28), and there is evidence of trans-placental transport of TFAs and presence of TFAs in umbilical cord blood $(28,29)$. It has also been hypothesized that TFAs could have a negative impact on fetal growth and development $(30,31)$; e.g., it has been suggested that higher levels of TFAs in maternal plasma are associated with low birth weight and short duration of gestation $(32,33)$. High intake of total TFAs during pregnancy may also influence growth patterns during infancy and childhood (34), but this has generally not been thoroughly examined. Partially hydrogenated fats, meat, and dairy fats are the main sources of TFAs (35), and according to the WHO recommendations, the intake of both iTFAs and rTFAs should be $<1 \%$ of the total energy intake (36).

The aims of this systematic literature review and meta-analysis were two-fold, e.g., to synthesize study results from (1) RCTs on the effect of n-3 LCPUFA supplementation and the dose, in healthy pregnant women, on both birth weight and weight during childhood, and (2) observational studies examining associations between n-3 LCPUFA or TFAs from maternal or neonatal blood or placenta tissue and birth weight and weight during childhood.

\section{MATERIALS AND METHODS}

This systematic literature review and meta-analysis was performed according to Preferred Reporting Items for Systematic reviews and Meta-Analysis (PRISMA) and registered at PROSPERO (no. CRD42019115892). In the analyses, we stratified the included RCTs according to the doses provided to the intervention groups. We stratified doses into three levels: below $300 \mathrm{mg} /$ day, 301-650 mg/day, and more than $650 \mathrm{mg} /$ day. This stratification was based on the recommended intake of n-3 LCPUFA by WHO, of which pregnant women should consume more than $300 \mathrm{mg} /$ day DHA+EPA (17). For the present review, we divided child weight according to the age groups $0-4$ years and 5-10 years of age, using the BMI-for-age growth charts, which suggest that child BMI declines between 0 and 4 years of age but increases again after 5 years of age. The included observational studies were similarly focused on healthy pregnant women and on the associations between the outcomes specified for the RCTs and maternal or infant blood or placenta samples of n-3 LCPUFA and TFA intake. The results from the RCTs and observational studies were both included in the evaluation of the evidence for a potential causal relationship between intake of n-3 LCPUFA or TFAs during pregnancy and fetal and child growth.

\section{Search Strategy}

Two databases, PubMed and EMBASE, were used to search for relevant articles in May 2019, using both MeSH terms and free terms. The following search terms were used: "Fatty Acids, Omega-3," "Trans Fatty Acids," "pregnancy," "Infant, Low Birth Weight," "Child Development," "Birth Weight," "Body Composition," "Body Weight," "Body Mass Index," "Growth 
and Development," "Growth," "infant," “child," and "adolescent" (Supplementary Table 3). The titles and abstracts of studies were used to screen articles, which were not in line with the inclusion criteria. The actual selection was conducted based on a full text screening of the papers that passed the initial screening.

Both the literature search and the assessment of the search results were performed independently by two reviewers, XR and $\mathrm{BV}$.

\section{Inclusion and Exclusion Criteria}

We included RCTs and observational studies. The selection criteria were based on the predefined population, intervention, comparison, outcomes (PICO) model. All years of publication were eligible for inclusion. Languages were restricted to English and Chinese.

RCTs were included based on the following PICO criteria:

Population: Healthy pregnant women and children.

Intervention: DHA and/or EPA as supplement(s) during pregnancy.

Comparison: No treatment groups.

Outcomes: Primary outcome is offspring weight; secondary outcome is BMI (BMI, BMI $z$ score, body composition, and fat distribution).

The included observational studies should:

1. Measure associations between levels of fatty acid and weight or BMI at different age groups (weight at birth, aged 0-4 years, and aged 5-10 years).

2. Associations between polyunsaturated and trans fatty acids consumption during pregnancy and offspring adiposity were presented based on fully adjusted models.

3. The sample tissue, from which levels of DHA and/or EPA were analyzed, should be maternal plasma or placental tissues.

4. The DHA content in the tissue should be expressed in percentage of total fatty acids.

We excluded cross-sectional studies with no control group, chart reviews, case series, commentaries (e.g., expert opinion, consensus statements), self-reported dietary information studies, and animal studies.

\section{Data Extraction}

The two reviewers, XR and BV, independently used Covidence to extract data from eligible RCT studies. Disagreement was resolved through discussion. The included information from RCTs were authors, publication year, number of participants, weight, or BMI at different ages (weight at birth, age 0-4 years, and age 5-10 years) and supplementation doses. Afterwards, included RCTs were divided into different groups according to n3 PUFA supplementation doses (0-300 mg/day, 301-650 mg/day, and more than $650 \mathrm{mg} /$ day).

The included information from observational studies were authors, publication year, results from each observational study, number of participants, percentage of boy participants, beta coefficient $(\beta)$, and 95\% confidence intervals (95\% CI) for associations between fatty acid levels and weight or BMI at different age groups (weight at birth, age $0-4$ years, and age 5-10 years).
In case of identification of multiple reports of a single RCT or observational study, the publication with most completed data was included, and if all reports had complete information, then it was treated as a single study with references made to all the publications. When several publications from one trial reported at different ages or outcomes, these publications were included in different meta-analyses. Some trials reported birth weight and offspring weight or BMI in two different publications. These two publications were included in different meta-analyses. In addition, at age 0-4 years and age 5-10 years, most included studies investigated weight or BMI around 2 and 5 years of age, respectively.

\section{Statistical Analyses}

Data from the RCTs or observational studies were quantitatively synthesized in a random effects meta-analysis to generate pooled effect estimates for birth weight or weight throughout childhood. The results from studies not possible to include in a meta-analysis were summarized narratively.

Continuous data from RCTs was analyzed by mean differences and $95 \%$ CI. According to the doses of fatty acid supplements from included RCTs, the meta-analysis was divided into three subgroups (0-300 mg/day, 301-650 mg/day, and more than $650 \mathrm{mg} /$ day). The two kinds of supplementation (DHA or $\mathrm{DHA}+\mathrm{EPA}$ ) were investigated using subgroup analyses following doses. Both BMI and BMI z score reflect weight during childhood and standardized mean difference (SMD) is used when metaanalyses assess the same outcome but measure BMI in different ways $(37,38)$. Therefore, in the meta-analysis of BMI at age 5-10 years, we combined offspring BMI and BMI $z$ score. For results from observational studies, adjusted $\beta$ correlation and corresponding 95\% CI between fatty acid levels and birth or child weight were used for all eligible studies. In addition, continuous outcomes were analyzed by $\beta$ and $95 \%$ CI. Meta-analyses combined data and $I^{2}$-values to quantify statistical heterogeneity, with an $I^{2}$-value $>50 \%$ considered to be substantial heterogeneity. We explored the possible cause(s) of heterogeneity when $I^{2}$ was $>50 \%$ by subgroup analyses.

Statistical analyses of RCTs were performed using Review manager 5.3 (RRID:SCR_003581), and statistical analyses of observational studies were performed using R 3.6.1.

\section{Study Quality Assessment}

Two reviewers (XR and BLV) assessed the quality of each RCT using the Cochrane risk of bias tool (39). Discrepancies between the two reviewers were resolved through discussion.

$\mathrm{XR}$ and BLV also assessed the quality of each observational study criteria outlined by the Risk of Bias in Non-Randomized Studies of Intervention (ROBINS-I) tool (40). Discrepancies were resolved through discussion. A Directed Acyclic Graph (DAG) was used to identify potential confounders (Supplementary Figure 1). Predefined confounders were maternal BMI (41), maternal smoking (42), and socioeconomic status (43).

For both RCTs and observational studies, the Grading of Recommendation Assessment, Development and Evaluation (GRADE) methodology was used to assess the quality of the 
evidence, with the four possible ratings of results: very low, low, moderate, and high. Downgrading was done, using the standard definitions risk of bias, indirectness, inconsistency, imprecision, and publication bias. A funnel plot was used to assess publication bias when more than 10 studies were included. If $<10$ studies were included in the funnel plots, the power of the test for detecting asymmetry would be too low (39).

Inconsistency was identified by test heterogeneity. The $I^{2}$ value was used to assess the degree of heterogeneity. If the $I^{2}$ value was $<50 \%$, heterogeneity was considered to be low or moderate. The overall quality of evidence was based on the lowest quality of the primary outcome.

\section{RESULTS}

\section{Study Selection}

A total of 1978 studies were identified through the literature search, of which 341 articles were excluded due to duplication. A total of 1,596 articles were excluded during the title and abstract screening $(n=1,503)$ and full text assessments $(n=93)$, due to different reasons. Study selection results are shown in Figure 1.

\section{Randomized Controlled Trials Description of Studies}

A total of 27 studies representing 19 trials met the inclusion criteria, all of them investigating influences of DHA or DHA and EPA supplementation during healthy pregnancies on birth weight or weight in childhood (44-70). In our protocol, we included children up to 18 years of age, but no studies measured the effect of n-3 LCPUFA or TFAs on weight after 10 years of age. We also planned to explore relationships between body composition, fat distribution, gender differences, and sub-group analyses of risk of bias, but not enough eligible studies were included. The papers were based on a total of 19 RCTs, as eight of the papers undertook long-term follow-up of the children: DOMInO trial $(51,52)$, NUHEA $(53,54)$, INFAT $(55,56)$, COPSAC $(57,58)$, trials from Mexico $(44,45)$, trials from the USA $(46,47)$, trials from Germany $(59,60)$, and trials from the Netherlands $(61,62)$. A total of 6,408 infants were investigated in relation to birth weight; the numbers of children included in relation to weight and BMI at age 0-4 years were 2,097 and 1,908 , respectively, and the numbers of children included in relation to weight and BMI at age 5-10 years were 3,477 and 3,445 , respectively. The studies' characteristics are summarized in Table 1.

Among the 27 studies, most ( $n=18$ studies) were published after 2011 (45-49, 52-58, 60, 62-66), 8 studies were published the decade before (2000-2010) (44, 50, 51, 59, 61, 67-69), and 1 study was published in 1992 (70). One trial was from Australia $(51,52)$; one was from Asia (65); nine were from the USA, of which eight did not specify ethnicity $(44-50,63,64)$; and one study only included African-American women (64). The remaining RCTs were from Europe (53-62, 66-70). The studies varied in size, ranging from 2,400 in the largest Australian $\operatorname{RCT}(51,52)$ to only 16 participants in a Spanish RCT (54), but most of the studies included between 20 and 500 pregnant women.

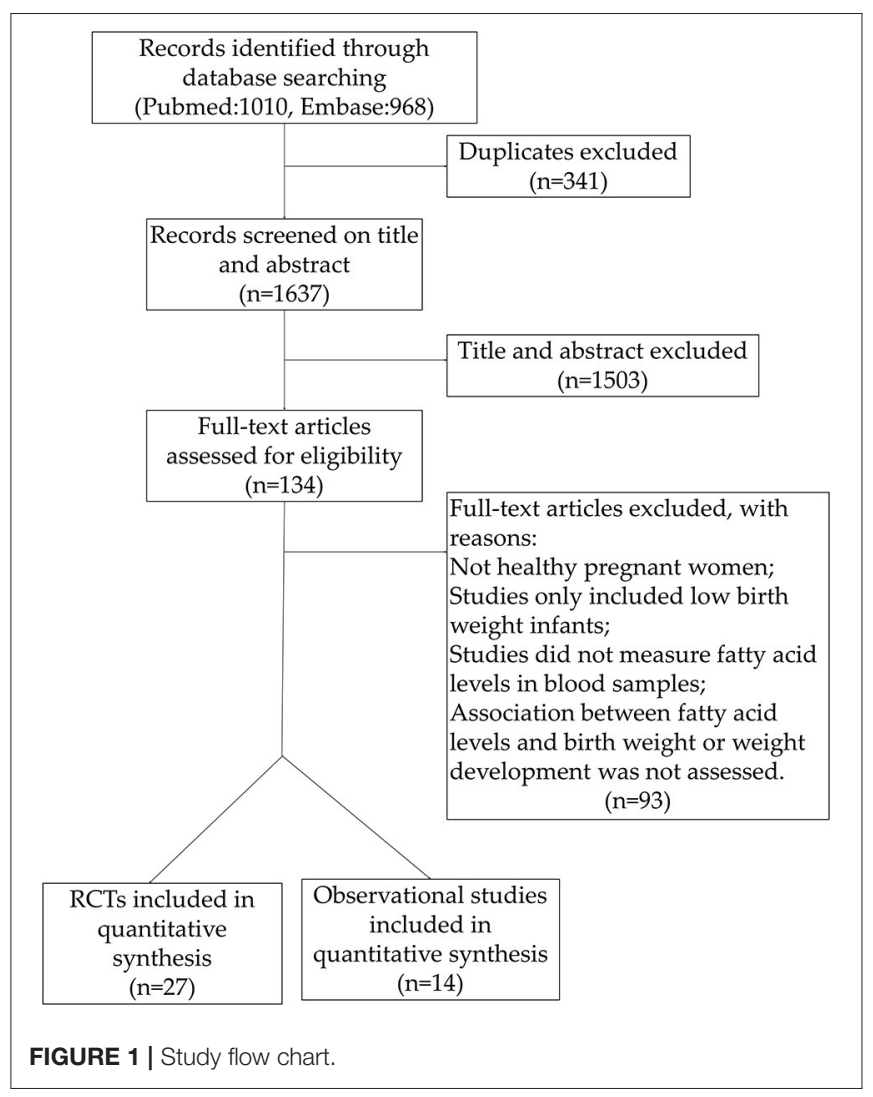

Some of the studies limited inclusion by maternal prepregnancy weight in the range of $50-92 \mathrm{~kg}(53,54)$ or prepregnancy BMI $<30 \mathrm{~kg} / \mathrm{m}^{2}(65)$, between 18 and $30 \mathrm{~kg} / \mathrm{m}^{2}$ $(55,56,66)$, or $<40 \mathrm{~kg} / \mathrm{m}^{2}(46,47,64)$. Nine studies excluded pregnant women with regular intake of marine supplements and other types of supplements $(49,51-56,66,70)$, or a high intake of fish $(44,45,49,64,67,70)$, milk $(59,60)$, or a history of drug use, smoking, or alcohol abuse $(51,52,55,56,59,60,63$, $64)$. Furthermore, two studies excluded pregnant women with vegetarian or vegan diets $(61,62)$.

Most of the studies used both DHA and EPA as supplements, with doses of supplementation ranging from around 200 to 2,200 mg/day n-3 LCPUFA. Seven studies used DHA as the single supplement with doses ranging from 200 to $600 \mathrm{mg}$ per day (44-50). The majority of the trials used fish oil (44-49, $51,52,55-63,65-67,69,70)$, but four trials supplied DHA or DHA and EPA with different foods such as milk, eggs, or cereal bars $(50,53,54,63,66,68)$. Most of the trials provided vegetable oil capsules to the participants in the control groups $(44-49,51,52,57,58,61-64,67,69,70)$, and where relevant, they gave the controls standard food products, eggs (50), or milk $(53,54,66)$. Only a few of the studies did not provide the control group with a comparator, but gave them only dietary counseling $(55,56)$.

Information on participants, supplementation, and duration of intervention and follow-up are described in Tables 1, 2. 
TABLE 1 | Summary of DHA supplementation trials.

\begin{tabular}{|c|c|c|c|c|c|c|c|c|}
\hline \multirow{2}{*}{$\begin{array}{l}\text { Authors, years } \\
\text { (country) }^{\star} \text { (primary } \\
\text { paper) }\end{array}$} & \multirow{2}{*}{$\begin{array}{l}\text { Authors, years* } \\
\text { (companion } \\
\text { papers) }\end{array}$} & \multirow[t]{2}{*}{ Intervention groups } & \multirow[t]{2}{*}{ Control groups } & \multirow[t]{2}{*}{ n-3 LCPUFA dose } & \multicolumn{2}{|c|}{ Number of participants } & \multirow{2}{*}{$\begin{array}{l}\text { Duration of } \\
\text { intervention }\end{array}$} & \multirow{2}{*}{$\begin{array}{l}\text { Duration of } \\
\text { anthropometric } \\
\text { follow-up }\end{array}$} \\
\hline & & & & & $\begin{array}{l}\text { Intervention } \\
\text { (boys \%) }\end{array}$ & $\begin{array}{l}\text { Control (boys } \\
\% \text { ) }\end{array}$ & & \\
\hline \multicolumn{9}{|c|}{ DHA supplementation } \\
\hline $\begin{array}{l}\text { Ramakrishnan et al. } \\
\text { (44) (Mexico) }\end{array}$ & $\begin{array}{l}\text { Gonzalez- } \\
\text { Casanova et al. } \\
\text { (45) }\end{array}$ & Algal DHA capsule & Olive oil capsule & $400 \mathrm{mg} /$ day & $487(46.1 \%)$ & 486 (45.9\%) & $\begin{array}{l}18-22 \text { weeks of } \\
\text { gestation until birth }\end{array}$ & $\begin{array}{l}\text { At birth and } 60 \\
\text { months }\end{array}$ \\
\hline $\begin{array}{l}\text { Carlson et al. (46) } \\
\text { (USA) }\end{array}$ & Hidaka et al. (47) & Algal DHA capsule & $\begin{array}{l}\text { A mix of } \\
\text { soybean and } \\
\text { corn oil capsule }\end{array}$ & $600 \mathrm{mg} /$ day & $154(49 \%)$ & 147 (54\%) & $\begin{array}{l}8-20 \text { weeks of gestation } \\
\text { until birth }\end{array}$ & $\begin{array}{l}\text { At birth and } 5 \\
\text { years }\end{array}$ \\
\hline $\begin{array}{l}\text { Mulder et al. (48) } \\
\text { (Canada) }\end{array}$ & & Algal DHA capsule & $\begin{array}{l}\text { A mix of } \\
\text { soybean and } \\
\text { corn oil capsule }\end{array}$ & $400 \mathrm{mg} /$ day & $104(40.4 \%)$ & $111(55 \%)$ & $\begin{array}{l}\text { Before } 16 \text { weeks of } \\
\text { gestation until birth }\end{array}$ & At birth \\
\hline $\begin{array}{l}\text { Harris et al. (49) } \\
\text { (USA) }\end{array}$ & & Algal DHA capsule & Olive oil capsule & $\begin{array}{l}300 \mathrm{mg} / \text { day or } 600 \\
\mathrm{mg} / \text { day }\end{array}$ & $\begin{array}{l}107 \\
117 \text { (no } \\
\text { information) }\end{array}$ & $\begin{array}{l}121 \text { (no } \\
\text { information) }\end{array}$ & $\begin{array}{l}16-20 \text { weeks of } \\
\text { gestation until birth }\end{array}$ & At birth \\
\hline $\begin{array}{l}\text { Smuts et al. (50) } \\
\text { (USA) }\end{array}$ & & DHA enriched eggs & Regular eggs & $\begin{array}{l}183.9 \pm 71.4 \mathrm{mg} / \text { day } \\
(\text { mean } \pm \mathrm{SD})\end{array}$ & $\begin{array}{l}18 \text { (no } \\
\text { information) }\end{array}$ & $\begin{array}{l}16 \text { (no } \\
\text { information) }\end{array}$ & $\begin{array}{l}24-28 \text { weeks of } \\
\text { gestation until birth }\end{array}$ & At birth \\
\hline \multicolumn{9}{|c|}{ DHA+EPA supplementation } \\
\hline $\begin{array}{l}\text { Makrides et al. (51) } \\
\text { (Australia) }\end{array}$ & $\begin{array}{l}\text { Muhlhausler et al. } \\
\text { (52) }\end{array}$ & Fish oil capsule & Vegetable oil & $\begin{array}{l}800 \text { mg/day DHA + } 100 \\
\text { mg/day EPA }\end{array}$ & $1,197(50.1 \%)$ & $1,202(49.8 \%)$ & $\begin{array}{l}\text { After } 21 \text { weeks of } \\
\text { gestation until birth }\end{array}$ & $\begin{array}{l}\text { At birth, and } 3 \text { and } \\
5 \text { years }\end{array}$ \\
\hline $\begin{array}{l}\text { Escolano-Margarit } \\
\text { et al. (54) (Germany, } \\
\text { Spain, Hungary) }\end{array}$ & Campoy et al. (53) & Fish oil-enriched milk & Milk & $\begin{array}{l}500 \text { mg/day DHA + } 150 \\
\mathrm{mg} / \text { day EPA }\end{array}$ & $43(53.5 \%)$ & $47(61.7 \%)$ & 20 weeks until birth & $\begin{array}{l}\text { At birth, and } 4 \text { and } \\
6.5 \text { years }\end{array}$ \\
\hline $\begin{array}{l}\text { Hauner et al. (55) } \\
\text { (Germany) }\end{array}$ & Brei et al. (56) & Fish oil capsule & $\begin{array}{l}\text { Dietary } \\
\text { counseling }\end{array}$ & $\begin{array}{l}1,020 \text { mg/day DHA + } \\
180 \text { mg/day EPA }\end{array}$ & $92(52 \%)$ & $96(52 \%)$ & $\begin{array}{l}15 \text { weeks of gestation to } \\
16 \text { weeks post-partum }\end{array}$ & $\begin{array}{l}\text { At birth, } 6 \text { weeks, } \\
4 \text { months, } 6 \\
\text { months, and } 2,3 \text {, } \\
4 \text {, and } 5 \text { years }\end{array}$ \\
\hline $\begin{array}{l}\text { Vinding et al. (57) } \\
\text { (Denmark) }\end{array}$ & Vinding et al. (58) & Fish oil capsule & Olive oil capsule & $\begin{array}{l}888 \mathrm{mg} / \text { day DHA + } \\
1,320 \mathrm{mg} / \text { day EPA }\end{array}$ & $304(48.2 \%)$ & $301(53.1 \%)$ & $\begin{array}{l}24 \text { weeks of gestation to } \\
1 \text { week post-partum }\end{array}$ & $\begin{array}{l}\text { At birth and } 6 \\
\text { years }\end{array}$ \\
\hline $\begin{array}{l}\text { Bergmann et al. (60) } \\
\text { (Germany) }\end{array}$ & $\begin{array}{l}\text { Bergmann et al. } \\
\text { (59) }\end{array}$ & $\begin{array}{l}\text { Combined } \\
\text { supplement [fish oil + } \\
\text { basic supplement + } \\
\text { fructooligosaccharide } \\
\text { (FOS)] }\end{array}$ & $\begin{array}{l}\text { Combined } \\
\text { supplement } \\
\text { (basic } \\
\text { supplement + } \\
\text { FOS) }\end{array}$ & $\begin{array}{l}200 \text { mg/day DHA + } 60 \\
\mathrm{mg} / \text { day EPA }\end{array}$ & $41(40 \%)$ & $74(47 \%)$ & $\begin{array}{l}\text { Mid-pregnancy to } 12 \\
\text { weeks post-partum }\end{array}$ & $\begin{array}{l}\text { At birth, } 21 \\
\text { months, and } 6 \\
\text { years }\end{array}$ \\
\hline $\begin{array}{l}\text { Van Goor et al. (61) } \\
\text { (Netherlands) }\end{array}$ & Van Goor et al. (62) & Fish oil capsule & $\begin{array}{l}\text { Soybean oil } \\
\text { capsule }\end{array}$ & $\begin{array}{l}220 \text { mg/day DHA + } 34 \\
\mathrm{mg} / \text { day EPA }\end{array}$ & $42(39 \%)$ & $36(61.8 \%)$ & $\begin{array}{l}15.6-17.4 \text { weeks of } \\
\text { gestation to } 12 \text { weeks } \\
\text { post-partum }\end{array}$ & $\begin{array}{l}\text { At birth and } 18 \\
\text { months }\end{array}$ \\
\hline $\begin{array}{l}\text { Judge et al. (63) } \\
\text { (USA) }\end{array}$ & & $\begin{array}{l}\text { Fish oil-enriched } \\
\text { cereal bar }\end{array}$ & $\begin{array}{l}\text { Corn oil cereal } \\
\text { bar }\end{array}$ & $\begin{array}{l}267 \text { mg/day DHA + } 34 \\
\text { mg/day EPA }\end{array}$ & $27(48.1 \%)$ & $21(66.7 \%)$ & 24 weeks until birth & At birth \\
\hline $\begin{array}{l}\text { Keenan et al. (64) } \\
\text { (USA) }\end{array}$ & & Fish oil capsule & $\begin{array}{l}\text { Soybean oil } \\
\text { capsule }\end{array}$ & $\begin{array}{l}450 \text { mg/day DHA + } 90 \\
\text { mg/day EPA }\end{array}$ & $34(58.8 \%)$ & 15 (46.7\%) & $\begin{array}{l}6 \text { weeks supply during } \\
\text { pregnancy }\end{array}$ & At birth \\
\hline
\end{tabular}



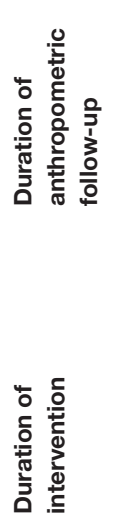

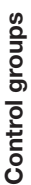

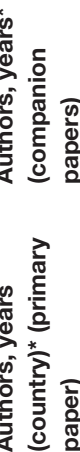$$
\text { (1) }
$$

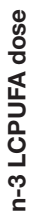

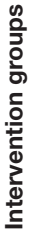

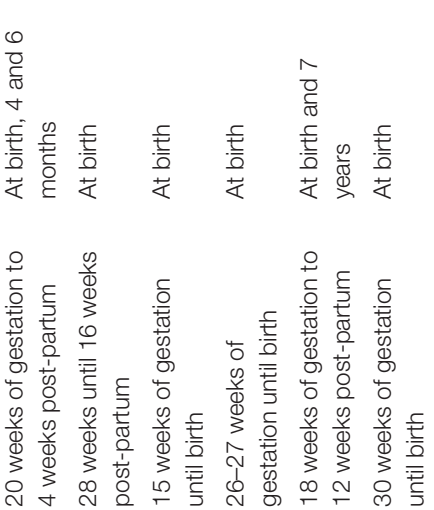

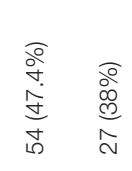
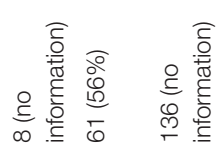

\section{Meta-Analysis Results From RCTs}

A total of 19 RCT studies were combined in a meta-analysis on birth weight $(44,46,48-51,54,55,57,60,61,63-71)$. The meta-analysis showed significant overall higher birth weight in the n-3 LCPUFA-supplemented compared to the control groups, irrespective of intake level [mean differences (MD) $57.5 \mathrm{~g}, 95 \%$ CI 26.2-88.9, $n=6,408, I^{2}=19 \%$, Figure 2, Table 3]. Stratified analysis of the effects of n-3 LCPUFA intervention doses showed a higher birth weight among the supplemented individual with doses higher than $650 \mathrm{mg} /$ day compared to the control groups, but not among individuals supplied with lower doses (MD $87.5 \mathrm{~g}$, 95\% CI 52.3-122.6, $n=3,831$, Figure 2, Table 3).

Eight RCT studies were included in the meta-analysis, which investigated supplementation of n-3 LCPUFA in pregnancy for development in weight or BMI at 0-4 years of age in the offspring $(52,54-56,59,62,65,66)$. The meta-analysis showed no difference in weight (MD $-0.05 \mathrm{~kg}, 95 \% \mathrm{CI}-0.3$ to $0.2, n=$ 2,097, Figure 3, Table 3) or BMI (MD 0.08, 95\% CI -0.3 to $0.4, n$ $=1,908$, Figure 4, Table 3), irrespective of dose.

Eight RCT studies investigated the importance of gestational DHA $(45,47)$ or DHA+EPA $(52,53,56,58,60,69)$ supplementation for offspring BMI, BMI $z$ score, or weight at 510 years of age. No differences in weight development between the control and the n-3 LCPUFA-supplemented groups were found (Figure 5, Table 3). A difference in combined BMI and BMI $z$ score was found where the n-3 LCPUFA intervention groups had slightly higher BMIs than the control groups (SMD $0.11,95 \%$ CI $0.04-0.18, n=3,445$, Figure 6, Table 3).

A total of two trials (four papers) were not included in previous meta-analyses (57-60).

\section{Grade}

The overall quality of the meta-analysis results for birth weight and weight or BMI and BMI $z$ scores at 5-10 years of age was rated as moderate quality, while the quality of meta-analysis results for weight at $0-4$ years was rated as low and the results for BMI at 0-4 years was rated as very low quality (Table 3).

\section{Risk of Bias}

The risk of bias for all included RCTs was assessed by the Cochrane risk of bias tool (39) and is shown in Supplementary Table 1 . The overall risk of bias was assessed; nine RCTs were rated as having low risk of bias $(44,45,48$, $51,52,57,58,64,65)$, and nine RCTs were unclear in relation to allocation concealment, blinding of outcome assessment, or incomplete outcome data $(46,53,54,59-63,68)$. Nine RCTs were found to have high risk of bias for more than one domain, and those articles were rated as having high risk of bias $(47,49,50,55$, $56,66,67,69,70)$.

The most common issue in relation to risk of bias was treatment allocation concealment; 16 RCTs did not describe this issue $(46,47,49,50,53,56,59-63,66-69,71)$. The method used for randomization sequence generation was unclear for six RCTs $(45,49,63,67,70,71)$ and another RCT did not use randomized methods (50). Four RCTs were rated as inadequate for blinding of patients and personnel or blinding of outcome assessors $(50,55,56,70)$. 
TABLE 2 | Summary of outcomes reported in the included RCTs.

\begin{tabular}{ll}
\hline n-3 LCPUFA doses & Studies investigated birth \\
\hline Weight & \\
0-300 mg/day n-3 LCPUFA & Bergmann et al. (59), Van Goor et al. (61), \\
& Judge et al. (63), Ostadrahimi et al. (65), \\
& Smuts et al. (50), Malcolm et al. (67), \\
& Sanjurjo et al. (68) \\
& Ramakrishnan et al. (44), \\
& Gonzalez-Casanova et al. (45), Escolano \\
& Margarit et al. (54), Campoy et al. (53), \\
& Carlson et al. (46), Mulder et al. (48), \\
& Harris et al. (49), Keenan et al. (64), \\
& Hurtado et al. (66)
\end{tabular}

More than 650 mg/day n-3 LCPUFA Makrides et al. (51), Hauner et al. (55), Vinding et al. (57), Helland et al. (69), Olsen et al. (70)

\section{BMI}

0-300 mg/day n-3 LCPUFA
301-650 mg/day n-3 LCPUFA
More than 650 mg/day n-3 LCPUFA

BMI z score

0-300 mg/day n-3 LCPUFA

301-650 mg/day n-3 LCPUFA

More than $650 \mathrm{mg} /$ day n-3 LCPUFA

Circumference (head, arm, Waits)

0-300 mg/day n-3 LCPUFA

301-650 mg/day n-3 LCPUFA

More than 650 mg/day n-3 LCPUFA

\section{Bergmann et al. (59)}

Judge et al. (63), Ostadrahimi et al., (65), Smuts et al. (50), Malcolm et al. (67)

Ramakrishnan et al. (44), Gonzalez-Casanova et al. (45), Carlson et al. (46), Harris et al. (49), Campoy et al. (53)

Brei et al. (56), Vinding et al. (57)

\section{BMI percentile}

More than 650 mg/day n-3 LCPUFA

Fat mass (g)/body fat (\%)

More than 650 mg/day n-3 LCPUFA Hauner et al. (55)
21 mohths) Bergmann et al. (59)

(4 years) Escolano Margarit et al. (54)

(3 years) Muhlhausler et al. (52)

(21 months) Bergmann et al. (60)

(3 years) Muhlhausler et al. (52)

(18 months) Van Goor et al. (62), (6 months) Ostadrahimi et al. (65)

Studies investigated $0-4$ years of age

(age of measure)

(21 mohths) Bergmann et al. (59), (18 months) Van Goor et al. (62), (6 months) Ostadrahimi et al. (65)

(3 years) Muhlhausler et al. (52), (3 years) Brei et al. (56)

(3 years) Muhlhausler et al. (52), (3 years) Brei et al. (56)

(3 years) Muhlhausler et al. (52), (3 years) Brei et al. (56)

(3 years) Muhlhausler et al. (52), (3 years) Hauner et al. (55)
Studies investigated 5-10 years of age (age of measure)

(6 years) Bergmann et al. (60)

(5 years) Gonzalez-Casanova et al.

(45), (5 years) Hidaka et al. (47)

(5 years) Muhlhausler et al. (52), (5 years) Brei et al. (56), (6 years) Vinding et al. (58)

(7 years) Helland et al. (69)

(6 years) Bergmann et al. (60)

(6.5 years) Campoy et al. (53)

(5 years) Muhlhausler et al. (52), (7 years) Helland et al. (69)

(6 years) Bergmann et al. (60)

(5 years) Gonzalez-Casanova et al.

(45), (5 years) Hidaka et al. (47)

(5 years) Muhlhausler et al. (52), (6

years) Vinding et al. (58)

(6 years) Bergmann et al. (60),

(5 years) Muhlhausler et al. (52), (5 years) Brei et al. (56), (6 years) Vinding et al. (58)

(5 years) Muhlhausler et al. (52), (5 years) Brei et al. (56)

(5 years) Muhlhausler et al. (52), (5 years) Hidaka et al. (47)

* n-3 LCPUFA doses: 301-650 mg/day n-3 LCPUFA.

Bold text: intervention groups showed higher result than control groups.

The meta-analyses for birth weight, weight and BMI at 0-4 years of age were influenced by risk of bias. A total of 19 RCTs were included in the meta-analysis for birth weight. Of the 19 RCTs, 6 RCTs had low risk of bias $(44,48,51,57,64,65), 6$ RCTs had unclear risk of bias $(46,54,60,61,63,68)$, and 7 RCTs had high risk of bias $(49,50,55,66,67,69,70)$. In the five RCTs that investigated child weight at age $0-4$ years, two RCTs had low risk of bias $(52,65)$, one had unclear risk of bias (59), and two had high risk of bias $(56,62)$. Four RCTs investigated child BMI at age 0-4 years, of which two RCTs had low risk of bias
$(52,54)$, one had unclear risk of bias (59), and one had high risk of bias (55). The included RCTs were mainly affected by a lack of information about allocation concealment, a lack of blinding, or loss to follow-up.

\section{Inconsistency}

The quality of the meta-analysis for BMI at age 0-4 years was downgraded due to inconsistency $\left(I^{2}=53 \%\right)$. In this group, the countries, doses, and delivery methods varied (Figure 4). One study was conducted in Australia (52), and three were from 


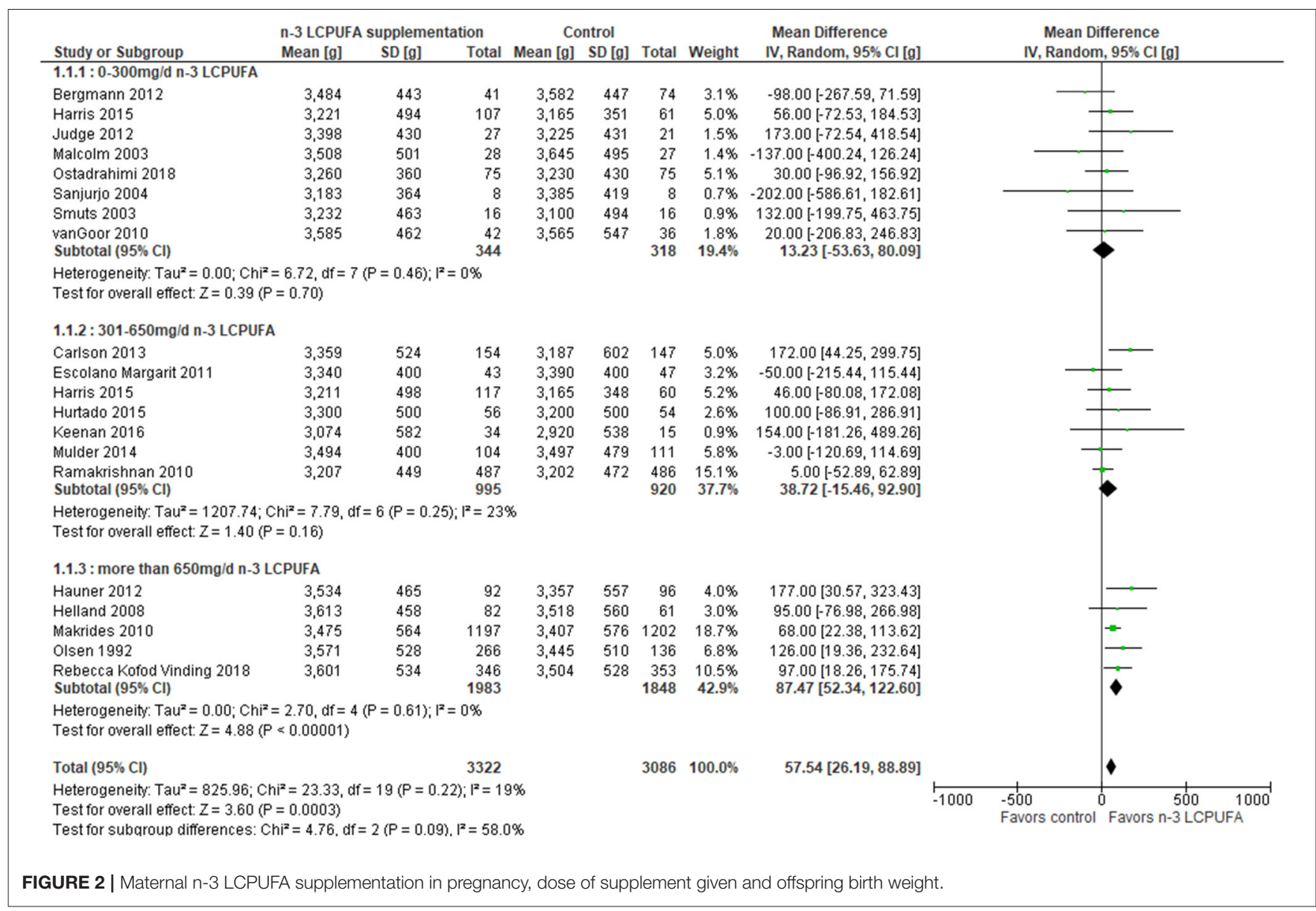

Europe; two were from Germany $(55,59)$ and one study collected data from Germany, Spain, and Hungary (54). Moreover, the doses of n-3 LCPUFA differed, ranging from $260 \mathrm{mg}$ /day (59) to $1,200 \mathrm{mg} /$ day (55), using different delivery methods: fish oil plus fructo-oligosaccharides (59), milk (54), or fish oil $(52,55)$. Heterogeneity for all analysis groups was not affected by stratified analysis (Table 3).

\section{Imprecision}

Meta-analyses for weight or BMI at age $0-4$ years and weight at age $5-10$ years were downgraded due to wide confidence intervals (Table 3).

\section{Publication Bias}

It was only possible to assess publication bias for the metaanalysis for birth weight. Here, the funnel plot showed no indication of publication bias (Supplementary Figure 2, Table 3).

\section{Observational Studies}

\section{Description of Studies and Participants}

In our protocol, we included children up to 18 years of age, but only one observational study investigated the effect of PUFAs on BMI up to 23 years of age (72). In total, 14 eligible observational studies investigated the relationship between blood levels of TFAs or n-3 LCPUFA during pregnancy or from cord blood or placental tissues, in relation to birth weight or weight in childhood (32, 33, 72-82). All the included observational studies are summarized in Table 4. A total of 11 of the studies were published after 2012 (72-78, 80-83), whereas three of the studies were published more than a decade ago $(32,33,79)$. Overall, mean maternal age ranged from 29 to 33 years. Only one study included more multiparous women than nulliparous (83). Most of the studies included slightly more boys than girls ranging from 50 to $54 \%(32,72-82)$, and one study included slightly more girls than boys (48.8\%) (33).

Information on participants and time of fatty acid measurements are given in Tables 4, 5 .

It was not possible to conduct a meta-analysis due to the fact that included studies used different statistical methods and different units for fatty acid levels in blood or tissue samples. All the observational studies included in this systematic review investigated different kinds of fatty acids (DHA, EPA, and TFAs) and outcomes (weight and BMI). Four of the studies reported fatty acid levels in $\mathrm{mg} / \mathrm{L}$ or $\mu \mathrm{g} / \mathrm{ml}(33,77,80,83)$, other studies presented in relative percentage $(\%, w / w)$ to total fatty acid levels $(32,72,73,76,78,79,81,82)$, one reported fatty acid levels in both ways $(74,75)$. Overall, four studies were from the Generation 




R Study from the Netherlands (74-77), three other studies also involved participants from the Netherlands $(33,72,79)$, one study was from the UK (80), one study was from Italy (81), three studies were from Asia $(73,78,82)$, one was from Canada (32), and, lastly, one study was from the USA [(83); Table 4].

\section{Results From the Observational Studies Birth Weight}

In total, eight studies examined the relationship between different fatty acids and birth weight $[(32,33,73,76,78,79,81,82)$; Table 4]. Three studies showed contradicting results as two studies found that a low maternal n-3 LCPUFA level was related to lower birth weight $(33,81)$, whereas another study showed that a high fetal DHA level was associated with low birth weight (81). One other study found that high n-3 LCPUFA status was related to lower birth weight (79), and one study found no association between n-3 LCPUFA and birth weight (82). DHA levels ranged from 3.34 to $5.76 \%$ and EPA levels ranged from 0.50 to $0.77 \%$.

Four studies investigated TFAs and birth weight $(32,33$, $77,79)$. Three studies found that high levels of TFAs during pregnancy were related to a lower weight at birth $(33,77,79)$, while one study found no association between TFAs and birth weight (32) Two studies calculated regression coefficients and showed the relation between maternal levels of different fatty acids and birth weight $(76,78)$.

\section{BMI at 0-4 Years of Age}

Five observational studies investigated the association between n-3 LCPUFA from maternal or neonatal blood and weight or BMI at $0-4$ years of age $(72,75,78,80,83)$. Four of them used regression coefficients, two measured fatty acids in $\mu \mathrm{g} / \mathrm{ml}$, and the DHA level ranged from 51.8 to $88.9 \mu \mathrm{g} / \mathrm{ml}$ and mean EPA levels were $5.1-10.9 \mu \mathrm{g} / \mathrm{ml}(80,83)$, while the other two studies measured fatty acids in weight percentage (wt\%), and DHA levels ranged from 4.69 to $5.0 \mathrm{wt} \%$ and mean EPA levels ranged from 0.6 to $0.69 \mathrm{wt} \%(74,78)$. The Moon et al. study investigated both DHA and EPA in relation to weight at 4 and 6 years of age and showed no association between maternal DHA and EPA level and BMI (80). Maslova et al. investigated both DHA and EPA in relation to BMI at age $0-4$ years and showed that high DHA was associated with lower BMI $z$ score (83).

No studies investigated the relation between TFA and weight or BMI at $0-4$ years of age.

\section{BMI at 5-10 Years of Age}

A total of five studies investigated the relationship between $n-3$ LCPUFA from maternal and neonatal blood and weight or BMI at 5-10 years of age $(72,74,78,80,83)$. Three studies showed no relationship between maternal n-3 LCPUFA status and weight (80) or BMI $(72,83)$ during childhood. One of these studies followed children from 6 months until 23 years of age, and the results showed no association between n-3 LCPUFA and BMI from infancy until young adulthood in boys and girls (72). Four studies used regression coefficients, and two of them measured fatty acids in $\mu \mathrm{g} / \mathrm{ml}(80,83)$, while the other two measured fatty acids in wt $\%(74,78)$. 


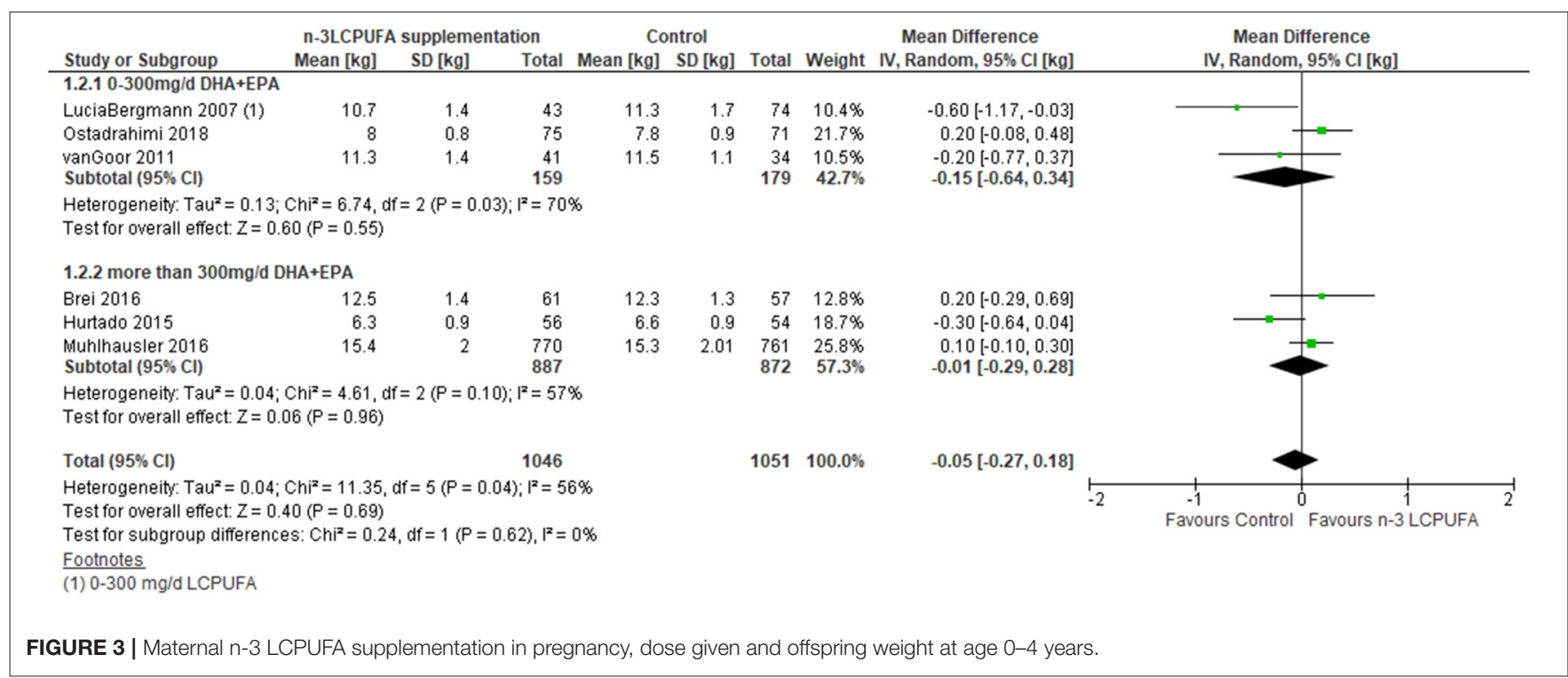

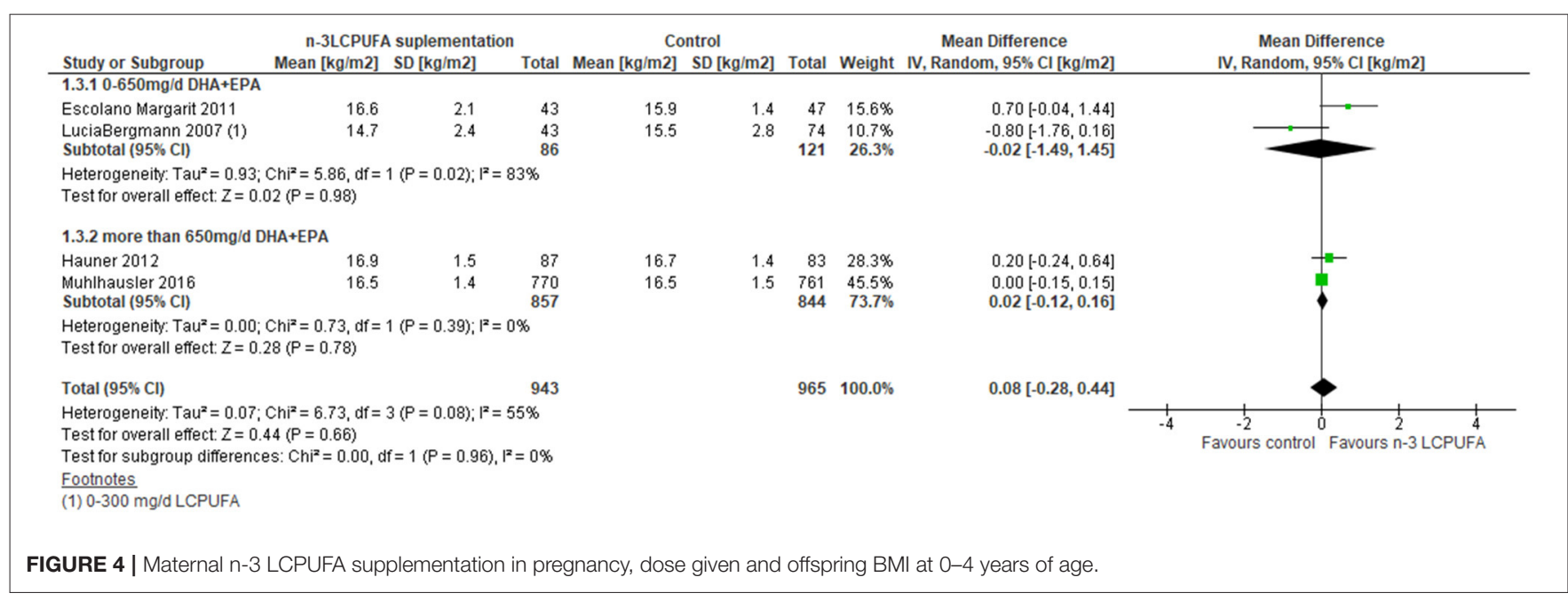

No studies investigated the relation between TFA and weight or BMI at 5-10 years of age.

\section{DISCUSSION}

The present meta-analysis of the RCTs showed that offspring birth weight was higher for $\mathrm{n}-3$ LCPUFA-supplemented than for placebo-supplemented pregnant women, especially when supplementation dose was high ( $>650 \mathrm{mg} /$ day). In addition, the supplementation with n-3 LCPUFA during pregnancy resulted in a modest increase in the BMI $z$ score but had no effect on BMI of the offspring at 5-10 years of age. BMI varies with age and sex in children, while these variations are accounted for when BMI $z$ scores are being used, which may explain why associations were seen only for BMI $z$ scores (84). Furthermore, this result was rated moderate quality only, according to GRADE guidelines.
Eight previous systematic reviews have investigated the effect of n-3 LCPUFA supplementation during pregnancy/lactation for child growth $(12,20-26)$. In our meta-analysis, we further included two RCTs (four papers) that had not been included in any of the previous meta-analyses (57-60). Furthermore, we restricted our search to include RCTs giving supplements to healthy pregnant women during pregnancy only. We found n3 LCPUFA supplementation to result in a higher birth weight, a finding that is in agreement with results from four of the eight previously published systematic reviews $(12,20,21,26)$. Our finding of an effect of maternal n-3 LCPUFA supplementation on BMI children aged 5-10 years is, however, not supported by any of the previous reviews. Indeed, three previous reviews found no support for an association when they investigated the effects of n3 LCPUFA supplementation during pregnancy and/or lactation for childhood BMI $(12,24,25)$. The conflicting results do not seem to depend on the period of when supplementation was 


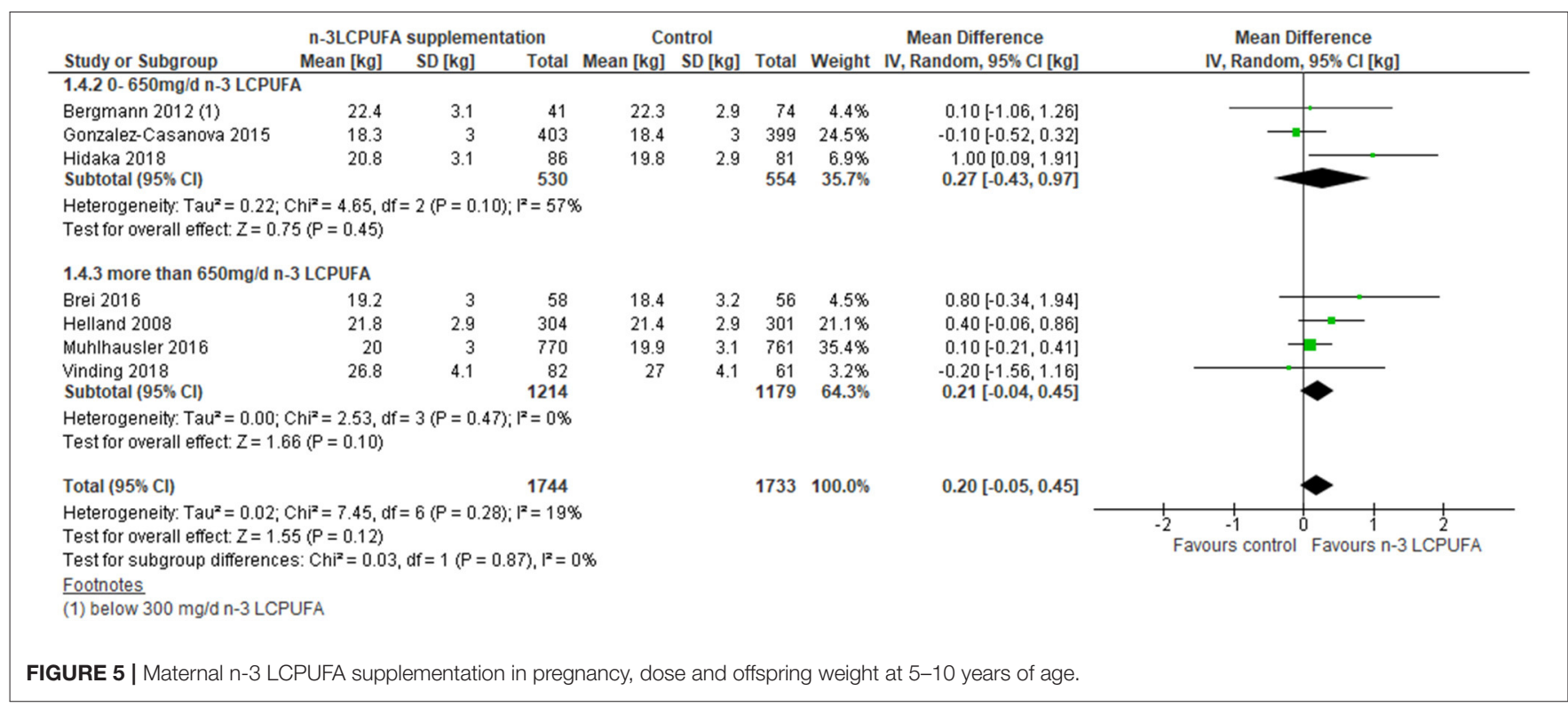

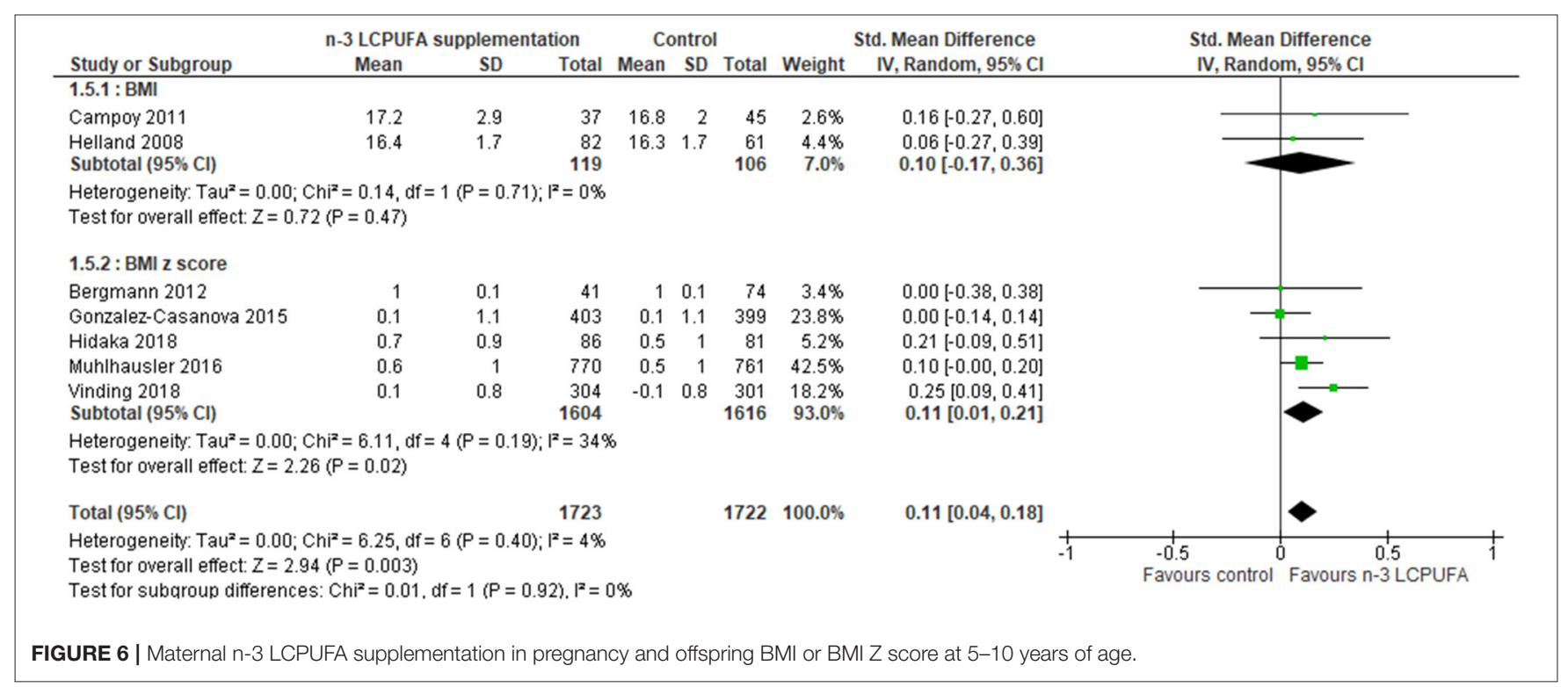

provided, but the reviews differed somewhat with respect to other selection criteria, especially to whether or not high risk or only healthy pregnant women were included.

We made some additional analyses to explore potential effect modifiers including the importance of the dose of n-3 LCPUFA, which provided important information to pursue in future RCTs. The relationship between n-3 LCPUFA and both birth weight and later BMI appear to be dose-dependent, and no effects could be detected with doses $<650 \mathrm{mg}$ /day. This is not surprising as a dose-response relationship is expected, but it indicates that the n3 LCPUFA intake has to be high in order to give rise to a relevant effect size. A dose $>650 \mathrm{mg} /$ day of n-3 LCPUFA is high compared to the intake supplied by the diet in most countries, but it is nevertheless feasible to achieve with a fish intake in accordance with the recommendations in many countries. Pregnant women are typically recommended to have a daily intake of $300 \mathrm{mg}$ of n-3 LCPUFA, which, according to this review, might not be optimal in relation to the birth weight of the baby. However, the results from our analysis showed a mean difference in birth weight of $57.5 \mathrm{~g}$ between the n-3 LCPUFA-supplemented groups and the control groups and a mean difference in BMI at 510 years of $0.09 \mathrm{~kg} / \mathrm{m}^{2}$, both of which may not be of major clinical relevance. In this regard, it has been reported that a higher birth weight of $586 \mathrm{~g}$ was related to a $25 \%$ higher odds of overweight at 15-20 years of age (OR 1.25, 95\% CI 1.061.48 ) and that a $1.83 \mathrm{~kg} / \mathrm{m}^{2}$ higher BMI at 5-7 years of age was also related to a high odds of overweight (OR 3.23, 95\% CI 2.56-4.07) (85). 


\section{Author, year, (country) Sample tissue, sample}

time and participant $(n$,

boys \%)

Meher et al. (73) (India)

Placental tissues (at delivery) DHA

( $n=64$, no information)

Vidakovic et al. (74)

(Netherlands)

Maternal plasma glyceroPL
in week 20.5 (median) $(n=$

(75)

Grootendorst et al. (76)

Grootendorst et al. (77)

Bernard et al. (78)

(Singapore) $4,830,50 \%)$

Maternal plasma glyceroPL in weeks $26-28(n=979$, no information)

Elias et al. (32) (Canada) Maternal and cord plasma TAG, PL, and CE in week 35 ( $n=70$, no information)

van Eijsden et al. (33) (the Maternal plasma PL in week Netherlands)

Dirix et al. (79) (the

Netherlands)

Moon et al. (80) (UK)

Stratakis et al. (72) (the

Netherlands)

Umbilical vein plasma PL birth $(n=250,54.8 \%)$

Cinelli et al. (81) (Italy)

Cord blood and maternal blood erythrocyte membranes at $12-24 \mathrm{~h}$

before birth $(n=607$

52.1\%)

Kitamura et al. (82) Maternal venous blood at 36-38 weeks and cord venous blood (erythrocyte membranes) $(n=212$, no

information) (Japan)
Type of fatty acid Confounders adjusted for
ALA, EPA+DHA n-3 LCPUFA

$\mathrm{BMI}$, age, and gestation age gender, maternal age, parity, educational level, alcohol use, folic acid supplement use, psychological symptoms and pregnancy complication, region.

Study center, ethnicity, child's sex, parity, fasting glucose levels, vitamin D levels, gestational weight gain at 26-28 weeks' gestation, maternal height and pre-pregnancy BMI, paternal height, familial income, maternal education and age.

TFAs, EPA, DHA No information

EPA, DPA, DHA,

DHA, TFAs

-3 LCPUFA, DHA Gestational weight gain, pre-pregnancy BMI, smoking, maternal age, offspring sex, gestational age, and parity.

EPA, DHA, DPA,

n-3LCPUFA

BMl at study entry, maternal height, parity, alcohol during pregnancy, weight gain during pregnancy, gestational age, infant

Social class and highest educational qualification, pre-pregnancy body mass index, smoking status in late pregnancy, maternal ag at delivery, parity, gestational weight, walking speed in late pregnancy, maternal mean daily intake of protein, fat and carbohydrate at 34 weeks gestation, the child's height and duration of breastfeeding.

Maternal BMl at study entry, maternal smoking in pregnancy, parental education, child age terms $\left(\right.$ age $^{0.5}$, age, age $\left.{ }^{3}\right)$, maternal age at birth, gestational weight gain, maternal alcohol intake in pregnancy, parity, breastfeeding status, and cross-products of each PUFA exposure with the child age terms.
BMI, smoking, gestational age at maternal blood sampling, child

Results

Low placenta DHA in low-birth-weight infants.

High n-3:n-6 PUFA ratio associated with birth weight $(\beta=0.76$ SD score, $95 \% \mathrm{Cl} 0.22,1.29, P=0.006)$. Maternal DHA and EPA levels not associated with BMl at 24 months or 6 years of age. High t18:1 was associated with low BW ( $\beta$ : $-0.10 ; 95 \% \mathrm{Cl}$ :

$-0.15,-0.04 ; P<0.001)$.

High DHA not associated with child weight and BMl from birth to 5 years of age.

Maternal TFAs and n-3 LCPUFA were not associated with BW.

TFAs were not related to the length of birth weight.

High TFA and low n-3 LCPUFA were associated with low BW (-52 to $-172 \mathrm{~g}$ and -56 to $-172 \mathrm{~g}$, respectively). 
TABLE 5 | Summary of outcomes and fatty acids for all 14 included observational studies.

\begin{tabular}{|c|c|c|c|}
\hline Outcome & $\begin{array}{l}\text { Studies only } \\
\text { measured DHA }\end{array}$ & $\begin{array}{l}\text { Studies } \\
\text { measured DHA } \\
\text { and EPA }\end{array}$ & $\begin{array}{l}\text { Studies } \\
\text { measured DHA } \\
\text { and other PUFA }\end{array}$ \\
\hline Birth weight & $\begin{array}{l}\text { Meher et al. (73) } \\
\text { Bernard et al. (78) } \\
\text { Dirix et al. }(79)^{\star}\end{array}$ & Elias et al. (32)* & $\begin{array}{l}\text { Grootendorst et al. } \\
(76) \\
\text { van Eijsden et al. } \\
(33)^{\star} \\
\text { Cinelli et al. (81) } \\
\text { Kitamura et al. (82) }\end{array}$ \\
\hline $\begin{array}{l}\text { Weight at } \\
1-4 \text { years of } \\
\text { age }\end{array}$ & Bernard et al. (78) & & Moon et al. (80) \\
\hline $\begin{array}{l}\text { BMl at } 1-4 \\
\text { years of age }\end{array}$ & Bernard et al. (78) & Maslova et al. (83) & $\begin{array}{l}\text { Jelena Vidakovic } \\
\text { et al. (75) } \\
\text { Stratakis et al. (72) }\end{array}$ \\
\hline $\begin{array}{l}\text { Weight at } \\
5-10 \text { years } \\
\text { of age }\end{array}$ & Bernard et al. (78) & & Moon et al. (80) \\
\hline $\begin{array}{l}\text { BMl at 5-10 } \\
\text { years of age }\end{array}$ & Bernard et al. (78) & Maslova et al. (83) & $\begin{array}{l}\text { Vidakovic et al. } \\
(74) \\
\text { Stratakis et al. (72) }\end{array}$ \\
\hline
\end{tabular}

*This study also measured TFA; another study only measured TFA (77).

\section{Summary of Results From Observational Studies in Relation to Other Studies in the Field}

Observational studies showed contradicting results relating maternal n-3 LCPUFA to low birth. Indeed, one found that low maternal n-3 LCPUFA was related to low birth weight and another found an association between high n-3 LCPUFA status at birth and low birth weight $(79,81)$. One study found no association (82). Three studies showed no relationship between maternal n-3 LCPUFA and weight $(80)$ or BMI $(72,83)$ during childhood, and in addition, one of these studies did not find an association with BMI measured at different times between ages 6 months and 23 years (72).

For the four observational studies that investigated maternal TFA intake and birth weight $(32,33,77,79)$, the results from three studies from the Netherlands indicated that a high maternal TFA level was related to $<50 \mathrm{~g}$ lower birth weight $(33,77,79)$, while one study from Canada showed no association between maternal TFA levels and birth weight (32). TFA are high in stick margarine, cakes, and French fries and occur naturally in meat and some milk products $(86,87)$. As many countries have legislations on the allowed TFA level, decreases in TFA content in the diet have been observed over the past one to two decades $(88,89)$. A previous study have reported that the individual effects on cardiometabolic risk and lipid profile of different sources of TFA are contentious (27). However, the studies included in this review did not report the sources of TFA. TFAs have been shown to cross the placenta (90) and may influence both PUFA transfer and metabolism $(34,91)$. One study, which estimated maternal consumption of TFAs in the first two trimesters by food frequency questionnaire 
(34), found that a high maternal TFA intake, particularly 16:1t during weeks 13-28 of pregnancy, was associated with a high fetal growth $z$ score. The authors argued that biomarkers may possibly reflect short-term intake while the assessed dietary intake of TFAs may be a better measure of long-term exposure (34).

\section{Comparing Results From RCTs and Observational Studies}

The RCTs showed that n-3 LCPUFA was related to a higher birth weight and to a higher BMI at 5-10 years, while the observational studies generally showed no relationship between n-3 LCPUFA and birth weight or BMI. The discrepant results may be related to selection bias and confounding (92), which can influence the relationship between n-3 LCPUFA levels and growth and may have been present in the observational studies but generally not in the RCT. Thus, since RCTs are able to control for selection and measure biases, RCTs generally offer stronger evidential support than observational studies alone (93). However, even if sample sizing in RCTs are determined by balancing feasibility and power of the study (94). RCTs have also been criticized for including small and selected sub-groups (95), which may hamper generalizability (92). Therefore, large and diverse observational cohort studies have been encouraged (96).

One further aspect that needs to be considered in the comparison of the results from the meta-analysis of the RCTs and the observational studies is dose. In our meta-analysis of RCTs, no effects were shown with doses of $<650 \mathrm{mg} /$ day n-3 LCPUFA supplementation. One review showed that the average n-3 LCPUFA intake in observational studies has been reported to be 75-149 mg/day in the USA and Canada, 250-550 $\mathrm{mg} /$ day in Europe, and $>550 \mathrm{mg} /$ day in Japan and Singapore (97), suggesting that intake doses may be too low to increase birth weight.

Finally, it should be noted that the RCTs included in the present review were of moderate GRADE quality only, because of risk of bias, and the results of the present analysis may further have been affected by publication bias and heterogeneity. Hence, the present meta-results should be interpreted with some caution.

\section{n-3 LCPUFA Intake and Status in Observational Studies}

The different results of the studies may also depend on the baseline levels of n-3 LCPUFA; e.g., if this level is high, there may be less room for improvement, and it may therefore be more difficult to find a significant difference even if high-dose supplements were given. Indeed, this review included studies from various countries, and it is well-known that intake and status of n-3 LCPUFA varies greatly between countries (98). The highest seafood n-3 fatty acid intake was found in Pacific Island nations, Denmark, South Korea, and Japan (97). These nations also had the highest levels of DHA and EPA measured from blood samples (99). Populations from Germany, Spain, the Netherlands, Singapore, and Australia were found to have low EPA+DHA blood levels, while levels were very low in Canada, the USA, Ireland, the UK, Italy, and Iran (99). Therefore, even if studies supplemented the same doses, they may still compare intervention and control groups, which are very different in terms of n-3 LCPUFA status.

The assessment of the importance of dose is further affected by the tissue sample used for evaluation of intake and status, e.g., fatty acid levels from different bio-materials seem to vary, and the level of DHA in cord plasma is higher than that in maternal plasma (100), while EPA status in infant plasma seems lower than that in maternal plasma (101). In the 14 included studies, three different tissues were used for extraction of lipids for the biomarker analysis. The most widely used tissue sample was plasma $(32,33,72,74-80)$, where lipid concentrations reflect recent maternal fat intake (24), as is probably also the case in the one study that used blood from the placenta (73). Three studies used erythrocytes as a bio-material (81-83), and this is considered to reflect long-term intake (24).

Blood samples in the studies included were collected at different times, ranging from 20.5 weeks into pregnancy to birth, and since it is well-known that both maternal erythrocytes and plasma DHA composition may decrease from the second trimester to delivery (102), studies may not be comparable. Also, the relative levels (\% wt/wt) of n-3 LCPUFA decline throughout pregnancy (103). All of the five observational studies included in the meta-analysis presented fatty acids in relative levels; four of them extracted fatty acids from plasma around mid-pregnancy, and one used the placenta at birth, hampering comparison.

\section{Maternal n-3 LCPUFA Supplementation}

DHA is transferred through the placenta and is rapidly stored in the fetal brain and retinal tissue (104). The fetus's need for nutrients is greater during the last trimester of pregnancy due to a rapid development of the brain and retina in the third trimester, and n-3 LCPUFA may therefore be most essential between the third trimester and 18 months of life (13). It has been suggested that the requirement in the third trimester of pregnancy is approximately $50 \mathrm{mg} /(\mathrm{kg} /$ day $) \mathrm{n}-3$ PUFA and $400 \mathrm{mg} /(\mathrm{kg} /$ day $)$ n-6 PUFA (105). It is therefore assumed that the period of supplementation or the assessment of maternal intake and status is relevant to consider in the evaluation of the results. All included RCTs started before the third trimester. The majority of the RCTs started supplementation around 20 weeks of gestation $(44,45,49,53,54,59,60,65,69)$ and five studies started earlier, from 8 weeks or before 17 weeks $(48,55,61,62,67)$. Only two RCTs started at 28 or 30 weeks of gestation. One RCT did not give information about when they started the intervention, but informed that they supplied n-3 LCPUFA for 6 weeks during pregnancy (64). In general, supplementation stopped at delivery, but 11 studies continued post-partum $(55-62,65,66,69)$. Jointly, the results indicate that dose as well as period of n-3 LCPUFA supplementation is important to consider.

It is also relevant to consider the comparator in RCTs. The different RCTs that were included in this review provided different sources of n-3 LCPUFA as supplements to participants. Different sources of oils have different quantity and quality of n3 PUFAs or a different DHA:EPA ratio $(106,107)$. A previous study suggested that DHA from an algal oil supplement can replace a fish oil supplement (108), but another study found n3 PUFA from plant oil is low in EPA and DHA (109). Some 
studies used PUFA enriched foods as supplements, which may significantly increase the fat profile and level in the human body (110). However, these kinds of foods required special storage conditions, since n-3 LCPUFA may oxidize to toxic peroxides (110). The fatty acid composition can also result in difference in the contribution to infant growth and body composition (111). The supplemented fish oils or seed oils contain some saturated fatty acids (up to $30-40 \%$ ) and even TFA $(112,113)$, which may explain some of the difference in the contribution to the metabolism in the pregnant woman and potentially contribute to associations with birth weight or childhood growth.

\section{Advantages and Limitations}

It is a strength of the present review that it is based on a large number of studies, that the included studies (both RCTs and observational studies) were identified from four continents and included 15 different countries. Since it has been suggested that BMI is not an accurate marker for obesity in children (114), the present meta-analysis included the results for weight, BMI, as well as BMI $z$ score. We collected data at different childhood ages, from birth to 10 years of age, enabling us to investigate the effects of n-3 LCPUFA and TFA throughout childhood.

On the other hand, most of the RCTs were from Europe, and data from some countries were still missed. Only one RCT was from Asia (65), and two RCTs were from Australia (51, 52), limiting generalization to other populations than mainly Caucasians. In addition, only two RCTs were conducted in a Newly Industrialized Country [Mexico $(44,45)]$ or a developing country [Iran (65)]. Various tissues were used to measure fatty acid levels, which will reflect maternal fatty acid intake to different extents.

\section{CONCLUSION}

In conclusion, this review and meta-analysis does support a relationship between maternal or neonatal $n-3$ fatty acid levels and offspring birth weight and weight development into childhood. This was specifically the case for high doses of DHA and/or EPA supplementation of $>650 \mathrm{mg} /$ day, whereas no association was found between low doses of supplementation and

\section{REFERENCES}

1. Ørskou J, Henriksen TB, Kesmodel U, Secher NJ. Maternal characteristics and lifestyle factors and the risk of delivering high birth weight infants. Obstetr Gynecol. (2003) 102:115-20. doi: 10.1016/S0029-7844(03)00402-2

2. Célind J, Hedlund M, Bygdell M, Sondén A, Elfvin A, Kindblom JM. Secular trends of birthweight in boys from 1950 to 2010. Pediatr Neonatol. (2019) 60:543-8. doi: 10.1016/j.pedneo.2019.01.012

3. Johnson W, Choh AC, Soloway LE, Czerwinski SA, Towne B, Demerath EW. Eighty-year trends in infant weight and length growth: the Fels Longitudinal Study. J Pediatr. (2012) 160:762-8. doi: 10.1016/j.jpeds.2011.11.002

4. Leddy MA, Power ML, Schulkin J. The impact of maternal obesity on maternal and fetal health. Rev Obstetr Gynecol. (2008) 1:170-8.

5. Meher A, Randhir K, Mehendale S, Wagh G, Joshi S. Maternal fatty acids and their association with birth outcome: a prospective weight development. Furthermore, we found some suggestion that high TFA levels during pregnancy may be related to a risk of low birth weight, while studies examining relations between TFA levels during pregnancy and infant or child weight were generally absent. Also, all effect sizes were relatively small and may not be considered clinically relevant. In the present review, we have analyzed results not only from RCTs but also from observational studies. Results from RCTs were rated as moderate quality. Thus, more high-quality long-term studies are still needed, especially studies that investigate high-dose supplementation during pregnancy of n-3 LCPUFA, effects of TFA, long-term follow-up in relation to infant and childhood weight and growth, as well as more studies from Asia.

\section{DATA AVAILABILITY STATEMENT}

The original contributions presented in the study are included in the article/Supplementary Material, further inquiries can be directed to the corresponding author/s.

\section{AUTHOR CONTRIBUTIONS}

XR contributed to the original draft. BV, JR, KW, SR, LL, BH, and IS contributed to methodology and critically reviewed this paper. All authors have read and agreed to the published version of the manuscript. All the authors contributed to the development of this paper.

\section{FUNDING}

The Parker Institute, Bispebjerg and Frederiksberg Hospital was supported by a core grant from the Oak Foundation (OCAY-13309). The funders had no role in the study design, collection, analysis and interpretation of data, writing of the paper, or decision to submit for publication.

\section{SUPPLEMENTARY MATERIAL}

The Supplementary Material for this article can be found online at: https://www.frontiersin.org/articles/10.3389/fnut.2021. 625596/full\#supplementary-material study. PLoS ONE. (2016) 11:e0147359. doi: 10.1371/journal.pone. 0147359

6. Hack M, Klein NK, Taylor HG. Long-term developmental outcomes of low birth weight infants. Future Child. (1995) 5:176-96.

7. Nakamuro M, Uzuki Y, Inui T. The effects of birth weight: does fetal origin really matter for long-run outcomes? Econo Lett. (2013) 121:53-8. doi: 10.1016/j.econlet.2013.07.003

8. Alexander BT, Henry Dasinger J, Intapad S. Effect of low birth weight on women's health. Clin Ther. (2014) 36:1913-23. doi: 10.1016/j.clinthera.2014.06.026

9. Kramer MS. Determinants of low birth weight: methodological assessment and meta-analysis. Bull World Health Organ. (1987) 65:663-737.

10. Wu G, Bazer FW, Cudd TA, Meininger CJ, Spencer TE. Maternal nutrition and fetal development. J Nutr. (2004) 134:2169-72. doi: $10.1093 /$ jn/134.9.2169 
11. Kabaran S, Besler HT. Do fatty acids affect fetal programming? J Health Popul Nutr. (2015) 33:14. doi: 10.1186/s41043-015-0018-9

12. Middleton P, Gomersall JC, Gould JF, Shepherd E, Olsen SF, Makrides M. Omega-3 fatty acid addition during pregnancy. Cochrane Database Syst Rev. (2018) 11:CD003402. doi: 10.1002/14651858.CD003402.pub3

13. Greenberg JA, Bell SJ, Ausdal WV. Omega-3 fatty acid supplementation during pregnancy. Rev Obstet Gynecol. (2008) 1:162-9.

14. Akerele OA, Cheema SK. A balance of omega-3 and omega-6 polyunsaturated fatty acids is important in pregnancy. J Nutr Intermed Metab. (2016) 5:23-33. doi: 10.1016/j.jnim.2016.04.008

15. Makrides M. The role of n-3 LCPUFA in pregnancy. OCL. (2011) 18:255-8. doi: 10.1051/ocl.2011.0408

16. Koletzko B, Lien E, Agostoni C, Bohles H, Campoy C, Cetin I, et al. The roles of long-chain polyunsaturated fatty acids in pregnancy, lactation and infancy: review of current knowledge and consensus recommendations. $J$ Perinatal Med. (2008) 36:5-14. doi: 10.1515/jpm.2008.001

17. Organization WH. Interim Summary of Conclusions and Dietary Recommendations on Total Fat \& Fatty Acids. Geneva: World Health Organization (2010). Available online at: https://www.who.int/nutrition/ topics/FFA_summary_rec_conclusion.pdf (accessed May 17, 2010).

18. Coletta JM, Bell SJ, Roman AS. Omega-3 fatty acids and pregnancy. Rev Obstet Gynecol. (2010) 3:163-71.

19. Thompson M, Hein N, Hanson C, Smith LM, Anderson-Berry A, Richter $\mathrm{CK}$, et al. Omega-3 fatty acid intake by age, gender, and pregnancy status in the United States: National Health and Nutrition Examination Survey 2003-2014. Nutrients. (2019) 11:177. doi: 10.3390/nu11010177

20. Kar S, Wong M, Rogozinska E, Thangaratinam S. Effects of omega-3 fatty acids in prevention of early preterm delivery: a systematic review and metaanalysis of randomized studies. Eur J Obstetr Gynecol Reproduct Biolo. (2016) 198:40-6. doi: 10.1016/j.ejogrb.2015.11.033

21. Li GL, Chen HJ, Zhang WX, Tong Q, Yan YE. Effects of maternal omega-3 fatty acids supplementation during pregnancy/lactation on body composition of the offspring: a systematic review and meta-analysis. Clin Nutr. (2018) 37:1462-73. doi: 10.1016/j.clnu.2017.08.002

22. Szajewska H, Horvath A, Koletzko B. Effect of n-3 long-chain polyunsaturated fatty acid supplementation of women with low-risk pregnancies on pregnancy outcomes and growth measures at birth: a metaanalysis of randomized controlled trials. Am J Clin Nutr. (2006) 83:1337-44. doi: $10.1093 / \mathrm{ajcn} / 83.6 .1337$

23. Saccone G, Berghella V. Omega-3 long chain polyunsaturated fatty acids to prevent preterm birth: a systematic review and meta-analysis. Obstetr Gynecol. (2015) 125:663-72. doi: 10.1097/aog.0000000000000668

24. Stratakis N, Gielen M, Chatzi L, Zeegers MP. Effect of maternal n-3 long-chain polyunsaturated fatty acid supplementation during pregnancy and/or lactation on adiposity in childhood: a systematic review and metaanalysis of randomized controlled trials. Eur J Clin Nutr. (2014) 68:1277-87. doi: 10.1038/ejen.2014.158

25. Vahdaninia M, Mackenzie H, Dean T, Helps S. The effectiveness of omega-3 polyunsaturated fatty acid interventions during pregnancy on obesity measures in the offspring: an up-to-date systematic review and meta-analysis. Eur J Nutr. (2019) 58:2597-613. doi: 10.1007/s00394-0181824-9

26. Imhoff-Kunsch B, Briggs V, Goldenberg T, Ramakrishnan U. Effect of n-3 long-chain polyunsaturated fatty acid intake during pregnancy on maternal, infant, and child health outcomes: a systematic review. Paediatr Perinatal Epidemiol. (2012) 26:91-107. doi: 10.1111/j.1365-3016.2012.01292.x

27. Verneque BJF, Machado AM, de Abreu Silva L, Lopes ACS, Duarte CK. Ruminant and industrial trans-fatty acids consumption and cardiometabolic risk markers: a systematic review. Critic Rev Food Sci Nutr. (2020) 1-11. doi: 10.1080/10408398.2020.1836471

28. Jamiol-Milc D, Stachowska E, Janus T, Barcz A, Chlubek D. Elaidic acid and vaccenic acid in the plasma of pregnant women and umbilical blood plasma. Pomeranian J Life Sci. (2015) 61:51-7. doi: 10.21164/pomjlifesci.52

29. Wada Y, Yoshida-Yamamoto S, Wada Y, Nakayama M, Mitsuda N, Kitajima H. Trans fatty acid accumulation in the human placenta. J Mass Spectrom. (2017) 52:139-43. doi: 10.1002/jms.3910

30. Dalainas I, Ioannou HP. The role of trans fatty acids in atherosclerosis, cardiovascular disease and infant development. Int Angiol. (2008) 27:146-56.
31. Larque E, Zamora S, Gil A. Dietary trans fatty acids in early life: a review. Early Hum Dev. (2001) 65(Suppl.):S31-41. doi: 10.1016/s0378-3782(01)00201-8

32. Elias SL, Innis SM. Infant plasma trans, $n-6$, and $n-3$ fatty acids and conjugated linoleic acids are related to maternal plasma fatty acids, length of gestation, and birth weight and length. Am J Clin Nutr. (2001) 73:807-14. doi: 10.1093/ajen/73.4.807

33. van Eijsden M, Hornstra G, van der Wal MF, Vrijkotte TG, Bonsel GJ. Maternal n-3, n-6, and trans fatty acid profile early in pregnancy and term birth weight: a prospective cohort study. Am J Clin Nutr. (2008) 87:887-95. doi: 10.1093/ajen/87.4.887

34. Cohen JF, Rifas-Shiman SL, Rimm EB, Oken E, Gillman MW. Maternal trans fatty acid intake and fetal growth. Am J Clin Nutr. (2011) 94:1241-7. doi: 10.3945/ajen.111.014530

35. Lichtenstein AH. Dietary trans fatty acids and cardiovascular disease risk: past and present. Curr Atheroscler Rep. (2014) 16:433. doi: 10.1007/s11883-014-0433-1

36. World Health Organization. Healthy Diet. (2018). Available online at: https:// www.who.int/news-room/fact-sheets/detail/healthy-diet (accessed February 15, 2019).

37. Cochrane Handbook for Systematic Reviews of Interventions Version 6.0. (2019). Available online at: www.training.cochrane.org/handbook (accessed April 2020).

38. da Costa BR, Nüesch E, Rutjes AW, Johnston BC, Reichenbach S, Trelle $S$, et al. Combining follow-up and change data is valid in meta-analyses of continuous outcomes: a meta-epidemiological study. J Clin Epidemiol. (2013) 66:847-55. doi: 10.1016/j.jclinepi.2013.03.009

39. Higgins JPT, Altman DG, Gøtzsche PC, Jüni P, Moher D, Oxman AD, et al. The Cochrane Collaboration's tool for assessing risk of bias in randomised trials. BMJ. (2011) 343:d5928. doi: 10.1136/bmj.d5928

40. Sterne JAC, Hernán MA, Reeves BC, Savović J, Berkman ND, Viswanathan $\mathrm{M}$, et al. ROBINS-I: a tool for assessing risk of bias in non-randomised studies of interventions. BMJ. (2016) 355:i4919. doi: 10.1136/bmj.i4919

41. Liu L, Ma Y, Wang N, Lin W, Liu Y, Wen D. Maternal body mass index and risk of neonatal adverse outcomes in China: a systematic review and meta-analysis. BMC Pregnancy Childbirth. (2019) 19:105. doi: $10.1186 / \mathrm{s} 12884-019-2249-\mathrm{z}$

42. Sexton M, Hebel JR. A clinical trial of change in maternal smoking and its effect on birth weight. JAMA. (1984) 251:911-5. doi: 10.1001/jama.1984.03340310025013

43. Spencer N, Bambang S, Logan S, Gill L. Socioeconomic status and birth weight: comparison of an area-based measure with the Registrar General's social class. J Epidemiol Commun Health. (1999) 53:495-8. doi: 10.1136/jech.53.8.495

44. Ramakrishnan U, Stein AD, Parra-Cabrera S, Wang M, Imhoff-Kunsch B, Juarez-Marquez S, et al. Effects of docosahexaenoic acid supplementation during pregnancy on gestational age and size at birth: randomized, doubleblind, placebo-controlled trial in Mexico. Food Nutr Bull. (2010) 31(Suppl. 2):S108-16. doi: 10.1177/15648265100312s203

45. Gonzalez-Casanova I, Stein AD, Hao W, Garcia-Feregrino R, BarrazaVillarreal A, Romieu I, et al. Prenatal supplementation with docosahexaenoic acid has no effect on growth through 60 months of age. J Nutr. (2015) 145:1330-4. doi: 10.3945/jn.114.203570

46. Carlson SE, Colombo J, Gajewski BJ, Gustafson KM, Mundy D, Yeast J, et al. DHA supplementation and pregnancy outcomes. Am J Clin Nutr. (2013) 97:808-15. doi: 10.3945/ajcn.112.050021

47. Hidaka BH, Thodosoff JM, Kerling EH, Hull HR, Colombo J, Carlson SE. Intrauterine DHA exposure and child body composition at 5 y: exploratory analysis of a randomized controlled trial of prenatal DHA supplementation. Am J Clin Nutr. (2018) 107:35-42. doi: 10.1093/ajcn/ nqx007

48. Mulder KA, King DJ, Innis SM. Omega-3 fatty acid deficiency in infants before birth identified using a randomized trial of maternal DHA supplementation in pregnancy. PLoS ONE. (2014) 9:e83764. doi: 10.1371/journal.pone.0083764

49. Harris MA, Reece MS, McGregor JA, Wilson JW, Burke SM, Wheeler $\mathrm{M}$, et al. The effect of omega-3 docosahexaenoic acid supplementation on gestational length: randomized trial of supplementation compared to 
nutrition education for increasing n-3 intake from foods. BioMed Res Int. (2015) 2015:8. doi: 10.1155/2015/123078

50. Smuts CM, Borod E, Peeples JM, Carlson SE. High-DHA eggs: feasibility as a means to enhance circulating DHA in mother and infant. Lipids. (2003) 38:407-14. doi: 10.1007/s11745-003-1076-y

51. Makrides M, Gibson RA, McPhee AJ, Yelland L, Quinlivan J, Ryan P. Effect of DHA supplementation during pregnancy on maternal depression and neurodevelopment of young children: a randomized controlled trial. JAMA. (2010) 304:1675-83. doi: 10.1001/jama.2010.1507

52. Muhlhausler BS, Yelland LN, McDermott R, Tapsell L, McPhee A, Gibson RA, et al. DHA supplementation during pregnancy does not reduce BMI or body fat mass in children: follow-up of the DHA to Optimize Mother Infant Outcome randomized controlled trial. Am J Clin Nutr. (2016) 103:1489-96. doi: 10.3945/ajcn.115.126714

53. Campoy C, Escolano-Margarit MV, Ramos R, Parrilla-Roure M, Csabi $\mathrm{G}$, Beyer J, et al. Effects of prenatal fish-oil and 5-methyltetrahydrofolate supplementation on cognitive development of children at $6.5 \mathrm{y}$ of age. Am J Clin Nutr. (2011) 94(Suppl. 6):1880-8s. doi: 10.3945/ajcn.110.001107

54. Escolano-Margarit MV, Ramos R, Beyer J, Csabi G, Parrilla-Roure M, Cruz F, et al. Prenatal DHA status and neurological outcome in children at age 5.5 years are positively associated. J Nutr. (2011) 141:1216-23. doi: 10.3945/jn.110.129635

55. Hauner H, Much D, Vollhardt C, Brunner S, Schmid D, Sedlmeier EM, et al. Effect of reducing the n-6:n-3 long-chain PUFA ratio during pregnancy and lactation on infant adipose tissue growth within the first year of life: an open-label randomized controlled trial. Am J Clin Nutr. (2012) 95:383-94. doi: 10.3945/ajcn.111.022590

56. Brei C, Stecher L, Much D, Karla M-T, Amann-Gassner U, Shen J, et al. Reduction of the $n-6: n-3$ long-chain PUFA ratio during pregnancy and lactation on offspring body composition: follow-up results from a randomized controlled trial up to $5 \mathrm{y}$ of age. Am J Clin Nutr. (2016) 103:1472-81. doi: 10.3945/ajcn.115.128520

57. Vinding RK, Stokholm J, Sevelsted A, Chawes BL, Bønnelykke K, Barman M, et al. Fish oil supplementation in pregnancy increases gestational age, size for gestational age, and birth weight in infants: a randomized controlled trial. $J$ Nutr. (2018) 149:628-34. doi: 10.1093/jn/nxy204

58. Vinding RK, Stokholm J, Sevelsted A, Sejersen T, Chawes BL, Bønnelykke $\mathrm{K}$, et al. Effect of fish oil supplementation in pregnancy on bone, lean, and fat mass at six years: randomised clinical trial. BMJ. (2018) 362:k3312. doi: 10.1136/bmj.k3312

59. Lucia Bergmann R, Bergmann KE, Haschke-Becher E, Richter R, Dudenhausen JW, Barclay D, et al. Does maternal docosahexaenoic acid supplementation during pregnancy and lactation lower BMI in late infancy? J Perinatal Med. (2007) 35:295-300. doi: 10.1515/jpm.2007.085

60. Bergmann RL, Bergmann KE, Richter R, Haschke-Becher E, Henrich W, Dudenhausen JW. Does docosahexaenoic acid (DHA) status in pregnancy have any impact on postnatal growth? Six-year followup of a prospective randomized double-blind monocenter study on low-dose DHA supplements. J Perinatal Med. (2012) 40:677-84. doi: 10.1515/jpm-2012-0080

61. van Goor SA, Dijck-Brouwer DA, Doornbos B, Erwich JJ, Schaafsma A, Muskiet FA, et al. Supplementation of DHA but not DHA with arachidonic acid during pregnancy and lactation influences general movement quality in 12-week-old term infants. Br J Nutr. (2010) 103:235-42. doi: 10.1017/s0007114509991528

62. van Goor SA, Dijck-Brouwer DA, Erwich JJ, Schaafsma A, Hadders-Algra M. The influence of supplemental docosahexaenoic and arachidonic acids during pregnancy and lactation on neurodevelopment at eighteen months. Prostagl Leukotr Essent Fatty Acids. (2011) 84:139-46. doi: 10.1016/j.plefa.2011.01.002

63. Judge MP, Cong X, Harel O, Courville AB, Lammi-Keefe CJ. Maternal consumption of a DHA-containing functional food benefits infant sleep patterning: an early neurodevelopmental measure. Early Hum Dev. (2012) 88:531-7. doi: 10.1016/j.earlhumdev.2011.12.016

64. Keenan K, Hipwell A, McAloon R, Hoffmann A, Mohanty A, Magee K. The effect of prenatal docosahexaenoic acid supplementation on infant outcomes in African American women living in low-income environments: a randomized, controlled trial. Psychoneuroendocrinology. (2016) 71:170-5. doi: 10.1016/j.psyneuen.2016.05.023

65. Ostadrahimi A, Salehi-pourmehr H, Mohammad-Alizadeh-Charandabi S, Heidarabady S, Farshbaf-Khalili A. The effect of perinatal fish oil supplementation on neurodevelopment and growth of infants: a randomized controlled trial. Eur J Nutr. (2018) 57:2387-97. doi: 10.1007/s00394-017-1512-1

66. Hurtado JA, Iznaola C, Pena M, Ruiz J, Pena-Quintana L, Kajarabille N, et al. Effects of maternal omega-3 supplementation on fatty acids and on visual and cognitive development. J Pediatr Gastroenterol Nutr. (2015) 61:472-80. doi: 10.1097/mpg.0000000000000864

67. Malcolm CA, McCulloch DL, Montgomery C, Shepherd A, Weaver LT. Maternal docosahexaenoic acid supplementation during pregnancy and visual evoked potential development in term infants: a double blind, prospective, randomised trial. Arch Dis Child Fetal Neonatal Ed. (2003) 88:F383-90. doi: 10.1136/fn.88.5.f383

68. Sanjurjo P, Ruiz-Sanz JI, Jimeno P, Aldamiz-Echevarria L, Aquino L, Matorras R, et al. Supplementation with docosahexaenoic acid in the last trimester of pregnancy: maternal-fetal biochemical findings. J Perinatal Med. (2004) 32:132-6. doi: 10.1515/jpm.2004.024

69. Helland IB, Smith L, Blomen B, Saarem K, Saugstad OD, Drevon CA. Effect of supplementing pregnant and lactating mothers with $n-3$ very-long-chain fatty acids on children's IQ and body mass index at 7 years of age. Pediatrics. (2008) 122:e472-9. doi: 10.1542/peds.2007-2762

70. Olsen SF, Sorensen JD, Secher NJ, Hedegaard M, Henriksen TB, Hansen HS, et al. Randomised controlled trial of effect of fish-oil supplementation on pregnancy duration. Lancet. (1992) 339:1003-7. doi: 10.1016/0140-6736(92)90533-9

71. De Groot RHM, Hornstra G, Van Houwelingen AC, Roumen F. Effect of alpha-linolenic acid supplementation during pregnancy on maternal and neonatal polyunsaturated fatty acid status and pregnancy outcome. Am J Clin Nutr. (2004) 79:251-60. doi: 10.1093/ajen/79.2.251

72. Stratakis N, Gielen M, Margetaki K, Godschalk RW, van der Wurff I, Rouschop S, et al. Polyunsaturated fatty acid levels at birth and child-to-adult growth: Results from the MEFAB cohort. Prostagl Leukotr Essent Fatty Acids. (2017) 126:72-8. doi: 10.1016/j.plefa.2017.09.004

73. Meher AP, Wadhwani N, Randhir K, Mehendale S, Wagh G, Joshi SR. Placental DHA and mRNA levels of PPARgamma and LXRalpha and their relationship to birth weight. J Clin Lipidol. (2016) 10:767-74. doi: 10.1016/j.jacl.2016.02.004

74. Vidakovic AJ, Gishti O, Voortman T, Felix JF, Williams MA, Hofman A, et al. Maternal plasma PUFA concentrations during pregnancy and childhood adiposity: the Generation R Study. Am J Clin Nutr. (2016) 103:1017-25. doi: $10.3945 /$ ajcn.115.112847

75. Jelena Vidakovic A, Santos S, Williams MA, Duijts L, Hofman A, Demmelmair $H$, et al. Maternal plasma n-3 and n-6 polyunsaturated fatty acid concentrations during pregnancy and subcutaneous fat mass in infancy. Obesity. (2016) 24:1759-66. doi: 10.1002/oby.21547

76. Grootendorst-van Mil NH, Tiemeier H, Steenweg-de Graaff J, Koletzko B, Demmelmair H, Jaddoe VWV, et al. Maternal plasma n-3 and n-6 polyunsaturated fatty acids during pregnancy and features of fetal health: fetal growth velocity, birth weight and duration of pregnancy. Clin Nutr. (2018) 37:1367-74. doi: 10.1016/j.clnu.2017.06.010

77. Grootendorst-van Mil NH, Tiemeier H, Steenweg-de Graaff J, Jaddoe VW, Steegers EA, Steegers-Theunissen RP. Maternal midpregnancy plasma trans 18:1 fatty acid concentrations are positively associated with risk of maternal vascular complications and child low birth weight. J Nutr. (2017) 147:398403. doi: 10.3945/jn.116.239335

78. Bernard JY, Tint MT, Aris IM, Chen LW, Quah PL, Tan KH, et al. Maternal plasma phosphatidylcholine polyunsaturated fatty acids during pregnancy and offspring growth and adiposity. Prostagl Leukotr Essent Fatty Acids. (2017) 121:21-9. doi: 10.1016/j.plefa.2017.05.006

79. Dirix CE, Kester AD, Hornstra G. Associations between term birth dimensions and prenatal exposure to essential and trans fatty acids. Early Hum Dev. (2009) 85:525-30. doi: 10.1016/j.earlhumdev.2009.05.001

80. Moon RJ, Harvey NC, Robinson SM, Ntani G, Davies JH, Inskip HM, et al. Maternal plasma polyunsaturated fatty acid status in late pregnancy is 
associated with offspring body composition in childhood. J Clin Endocrinol Metab. (2013) 98:299-307. doi: 10.1210/jc.2012-2482

81. Cinelli G, Fabrizi M, Rava L, Signore F, Vernocchi P, Semeraro M, et al. Association between maternal and foetal erythrocyte fatty acid profiles and birth weight. Nutrients. (2018) 10:402. doi: 10.3390/nu10040402

82. Kitamura Y, Kogomori C, Hamano H, Maekawa I, Shimizu T, Shiga S. Fatty acid composition of the erythrocyte membranes varies between early-term, full-term, and late-term infants in Japan. Ann Nutr Metab. (2018) 73:335-43. doi: 10.1159/000494886

83. Maslova E, Rifas-Shiman SL, Olsen SF, Gillman MW, Oken E. Prenatal n-3 long-chain fatty acid status and offspring metabolic health in early and mid-childhood: results from Project Viva. Nutr Diabetes. (2018) 8:29. doi: 10.1038/s41387-018-0040-2

84. Must A, Anderson SE. Body mass index in children and adolescents: considerations for population-based applications. Int J Obes. (2006) 30:5904. doi: 10.1038/sj.ijo.0803300

85. Evensen E, Emaus N, Kokkvoll A, Wilsgaard T, Furberg AS, Skeie G. The relation between birthweight, childhood body mass index, and overweight and obesity in late adolescence: a longitudinal cohort study from Norway, the Tromso Study, Fit Futures. BMJ open. (2017) 7:e015576. doi: 10.1136/bmjopen-2016-015576

86. Lichtenstein AH. Atherosclerosis. In: Caballero B, editor. Encyclopedia of Food Sciences and Nutrition. 2nd ed. Oxford: Academic Press. (2003) p. 338-47.

87. Eshak ES, Yamagishi K, Iso H. Dietary fat and risk of cardiovascular disease. In: Vasan RS, Sawyer DB, editors. Encyclopedia of Cardiovascular Research and Medicine. Oxford: Elsevier. (2018) p. 60-89.

88. Craig-Schmidt MC. World-wide consumption of trans fatty acids. Atheroscler Suppl. (2006) 7:1-4. doi: 10.1016/j.atherosclerosissup.2006.04.001

89. Martin-Saborido C, Mouratidou T, Livaniou A, Caldeira S, Wollgast J. Public health economic evaluation of different European Union-level policy options aimed at reducing population dietary trans fat intake. Am J Clin Nutr. (2016) 104:1218-26. doi: 10.3945/ajcn.116.136911

90. Innis SM. Fatty acids and early human development. Early Hum Dev. (2007) 83:761-6. doi: 10.1016/j.earlhumdev.2007.09.004

91. Innis SM. Trans fatty intakes during pregnancy, infancy and early childhood. Atheroscler Suppl. (2006) 7:17-20. doi: 10.1016/j.atherosclerosissup.2006.04.005

92. Safieddine M, Chapelle C, Ollier E, Ferdynus C, Bertoletti L, Mismetti $\mathrm{P}$, et al. Compared to randomized studies, observational studies may overestimate the effectiveness of DOACs: a metaepidemiological approach. J Clin Epidemiol. (2021) 130:49-58. doi: 10.1016/j.jclinepi.2020. 10.013

93. Sami T, Sedgwick P. Do RCTs provide better evidence than observational studies? Opticon1826. (2011) 6:1-3. doi: 10.5334/opt.111103

94. Vishwakarma G. Sample Size and Power Calculation. Talha Sami \& Philip Sedgwick (2017). p. 234-46.

95. Moustafa F, Pesavento R, di Micco P, González-Martínez J, Quintavalla R, Peris M-L, et al. Real-life use of anticoagulants in venous thromboembolism with a focus on patients with exclusion criteria for direct oral anticoagulants. Clin Pharmacol Therap. (2018) 103:684-91. doi: 10.1002/ cpt.781

96. Furberg BD, Furberg CD. (eds.). What are the Strengths of Observational Studies? In: Evaluating Clinical Research. New York, NY: Springer (2007). p. 35-7.

97. Micha R, Khatibzadeh S, Shi P, Fahimi S, Lim S, Andrews KG, et al. Global, regional, and national consumption levels of dietary fats and oils in 1990 and 2010: a systematic analysis including 266 country-specific nutrition surveys. BMJ. (2014) 348:g2272. doi: 10.1136/bmj.g2272

98. Otto SJ, Houwelingen AC, Antal M, Manninen A, Godfrey K, LopezJaramillo P, et al. Maternal and neonatal essential fatty acid status in phospholipids: an international comparative study. Eur J Clin Nutr. (1997) 51:232-42. doi: 10.1038/sj.ejcn.1600390

99. Stark KD, Van Elswyk ME, Higgins MR, Weatherford CA, Salem N. Global survey of the omega-3 fatty acids, docosahexaenoic acid and eicosapentaenoic acid in the blood stream of healthy adults. Progr Lipid Res. (2016) 63:132-52. doi: 10.1016/j.plipres.2016.05.001

100. Gil-Sánchez A, Larqué E, Demmelmair H, Acien MI, Faber FL, Parrilla JJ, et al. Maternal-fetal in vivo transfer of [13C]docosahexaenoic and other fatty acids across the human placenta $12 \mathrm{~h}$ after maternal oral intake. Am J Clin Nutr. (2010) 92:115-22. doi: 10.3945/ajcn.2010.29589

101. Huang HL, Chuang LT, Li HH, Lin CP, Glew RH. Docosahexaenoic acid in maternal and neonatal plasma phospholipids and milk lipids of Taiwanese women in Kinmen: fatty acid composition of maternal blood, neonatal blood and breast milk. Lipids Health Dis. (2013) 12:27. doi: 10.1186/1476-511x-12-27

102. Kawabata T, Kagawa Y, Kimura F, Miyazawa T, Saito S, Arima T, et al. Polyunsaturated fatty acid levels in maternal erythrocytes of Japanese women during pregnancy and after childbirth. Nutrients. (2017) 9:245. doi: $10.3390 /$ nu9030245

103. Takeuchi H, Sugano M. Industrial trans fatty acid and serum cholesterol: the allowable dietary level. J Lipids. (2017) 2017:9751756. doi: 10.1155/2017/9751756

104. Rees A, Sirois S, Wearden A. Prenatal maternal docosahexaenoic acid intake and infant information processing at $4.5 \mathrm{mo}$ and $9 \mathrm{mo}$ : a longitudinal study. PLoS ONE. (2019) 14:e0210984. doi: 10.1371/journal.pone.0210984

105. Cetin I, Alvino G, Cardellicchio M. Long chain fatty acids and dietary fats in fetal nutrition. J Physiol. (2009) 587(Pt 14):3441-51. doi: 10.1113/jphysiol.2009.173062

106. Tou JC, Altman SN, Gigliotti JC, Benedito VA, Cordonier EL. Different sources of omega-3 polyunsaturated fatty acids affects apparent digestibility, tissue deposition, and tissue oxidative stability in growing female rats. Lipids Health Dis. (2011) 10:179. doi: 10.1186/1476-511X-10-179

107. Hammad SS, Jones PJ. Dietary fatty acid composition modulates obesity and interacts with obesity-related genes. Lipids. (2017) 52:803-22. doi: 10.1007/s11745-017-4291-9

108. Ryan L, Symington AM. Algal-oil supplements are a viable alternative to fishoil supplements in terms of docosahexaenoic acid (22:6n-3; DHA). J Funct Foods. (2015) 19:852-8. doi: 10.1016/j.jff.2014.06.023

109. Lenihan-Geels G, Bishop KS, Ferguson LR. Alternative sources of omega-3 fats: can we find a sustainable substitute for fish? Nutrients. (2013) 5:1301-15. doi: 10.3390/nu5041301

110. Kolanowski W, Laufenberg G. Enrichment of food products with polyunsaturated fatty acids by fish oil addition. Eur Food Res Technol. (2005) 222:472-7. doi: 10.1007/s00217-005-0089-8

111. Ailhaud G, Guesnet P. Fatty acid composition of fats is an early determinant of childhood obesity: a short review and an opinion. Obes Rev. (2004) 5:21-6. doi: 10.1111/j.1467-789X.2004.00121.x

112. Mason RP, Sherratt SCR. Omega-3 fatty acid fish oil dietary supplements contain saturated fats and oxidized lipids that may interfere with their intended biological benefits. Biochem Biophys Res Commun. (2017) 483:4259. doi: 10.1016/j.bbrc.2016.12.127

113. Delmonte P, Milani A, Bhangley S. Structural determination and occurrence in ahiflower oil of stearidonic acid trans fatty acids. Lipids. (2018) 53:255-66. doi: 10.1002/lipd.12009

114. Javed A, Jumean M, Murad MH, Okorodudu D, Kumar S, Somers VK, et al. Diagnostic performance of body mass index to identify obesity as defined by body adiposity in children and adolescents: a systematic review and meta-analysis. Pediatr Obes. (2015) 10:234-44. doi: 10.1111/ijpo.242

Conflict of Interest: The authors declare that the research was conducted in the absence of any commercial or financial relationships that could be construed as a potential conflict of interest.

Copyright (C) 2021 Ren, Vilhjálmsdóttir, Rohde, Walker, Runstedt, Lauritzen, Heitmann and Specht. This is an open-access article distributed under the terms of the Creative Commons Attribution License (CC BY). The use, distribution or reproduction in other forums is permitted, provided the original author(s) and the copyright owner(s) are credited and that the original publication in this journal is cited, in accordance with accepted academic practice. No use, distribution or reproduction is permitted which does not comply with these terms. 